\title{
ESTIMATIVAS DE PARÂMETROS GENÉTICOS DE CARACTERÍSTICAS DE CARCAÇAS FEITAS POR ULTRA-SONOGRAFIA EM BOVINOS DA RAÇA NELORE
}

\section{Luís Gustavo Girardi Figueiredo}

Dissertação de Mestrado apresentada à Comissão de Pós-Graduação da Faculdade de Zootecnia e Engenharia de Alimentos da USP em 25 de abril de 2001, como parte dos requisitos para a obtenção do Título de Mestre em Zootecnia, na área de Concentração de Qualidade e Produtividade Animal. 


\section{FICHA CATALOGRÁFICA preparada pela}

Biblioteca da Faculdade de Zootecnia e Engenharia de Alimentos da Universidade de São Paulo

Figueiredo, Luís Gustavo Girardi

F475e Estimativa de parâmetros genéticos de características de carcaça feitas por ultrassonografia em bovinos da raça Nelore / Luís Gustavo Girardi Figueiredo. - Pirassununda, 2001. Dissertação (Mestrado) - Faculdade de Zootecnia e Engenharia de Alimentos - Universidade de São Paulo, 2001. Departamento de Ciências Básicas Área de concentração: Qualidade e Produtividade Animal Orientador: Prof. Dr. Joanir Pereira Eler

Unitermos: 1. Bovinos, raça Nelore 2. Carcaça, área de olho de lombo 3. Carcaça, avaliação in vivo 4. Carcaça, gordura subcutânea, espessura 5. Melhoramento animal, parâmetro genético I. Título. 
Lembrete

Se procurar bem, você acaba encontrando não a explicação (duvidosa) da vida, mas a poesia (inexplicável) da vida

Carlos Drummond de Andrade

À minha família Antonio, Vera e César, pelo carinho e incentivo dados durante esta jornada e toda a minha vida

À Paula, companheira e amiga com quem pude contar nas horas finais deste trabalho. 


\section{AGRADECIMENTOS}

A Deus que possibilitou estar aqui neste momento entre pessoas amigas.

Ao Professor Doutor Joanir Pereira Eler pela orientação, não somente em minha vida acadêmica, mas como também em minha vida profissional.

Ao Professor Doutor José Bento Sterman Ferraz por sua importante colaboração no projeto e principalmente pela amizade e compreensão.

À Faculdade de Zootecnia e Engenharia de Alimentos da Universidade de São Paulo, pela importância em minha vida em toda minha formação.

À empresa Agro-Pecuária CFM Ltda., principalmente nas pessoas de Fábio Dias, Rodney Hobbs e James Eagers pela oportunidade de realização deste trabalho.

À Manah Agropastoril Ltda., principalmente ao senhor Eduardo Penteado Cardoso pela oportunidade de realização.

Aos colegas de graduação Biza e Feio, com quem tive a oportunidade de reencontrar no mestrado e a possibilidade de dividirmos a mesma moradia. 
Aos amigos Saulo, Sandro, Ricardo e Camila com quem hoje moro, que me apoiaram em horas difíceis e me chamaram a atenção para coisas que às vezes não estava enxergando.

À Elisângela, amiga que me ajudou a solucionar todos os meus problemas computacionais.

Aos colegas de pós Evandro, William, Marcelo, Ivan e Erica pela convivência no GMA.

Aos colegas Marcinha, Dany, Silvia, Bentinho, Renato, Zé Luiz e Tigueis pela convivência tanto no alojamento como pelos bares da vida.

À FAPESP pelo apoio financeiro dado a este projeto.

Aos funcionários das fazendas em estivemos fazendo coletas.

À Soraya e Rosangela pelo apoio logístico.

A todos funcionários da FZEA que de alguma maneira contribuíram com o desenvolvimento deste projeto.

A todos que de alguma maneira ajudaram no desenvolvimento deste projeto ou o no enriquecimento de minha formação profissional e humana. 
Página

LISTA DE FIGURAS iii

LISTA DE TABELAS vi

Lista de ABREVIATURAS vii

LISTA DE SÍMBOLOS viii

RESUMO ix

Abstract $\quad x$

1 INTRODUÇÃo E REVISÃo BIBLIOGRÁFICA 1

2 MATERIAL E MÉtodos $\quad 13$

$\begin{array}{ll}\text { 3.1. Local da colheita de dados } & 13\end{array}$

$\begin{array}{ll}\text { 3.2. Equipamento } & 14\end{array}$

$\begin{array}{ll}\text { 3.2.1. Aparelho } & 14\end{array}$

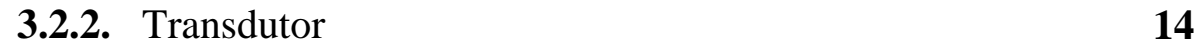

$\begin{array}{ll}\text { 3.3. Local das medidas de ultra-sonografia } & 15\end{array}$

3.4. Procedimento de Coleta 15

3.5. Formação do Banco de Dados 17

3.5.1. Fazendas São Francisco e Cherubim 17

$\begin{array}{lll}\text { 3.5.2. Fazenda Mundo Novo } & 18\end{array}$

$\begin{array}{lr}\text { 3.6. Modelos } & 19\end{array}$

3.6.1. Efeitos Fixos 20

3.6.2. Efeitos Genéticos 23

3.7. Metodologia de Análise Genética 23

3.8. Seleção Indireta

4. Resultados E Discussão 25

3.1. Herdabilidade 25 
3.1.1. Medidas Fei

3.1.2. tas por Ultra-sonografia

25

4.1.2.1. Área de Olho de Lombo 25

4.1.2.2. Espessura de Gordura Subcutânea 27

3.1.3. Medidas de Desenvolvimento Ponderal 31

4.1.3.1. Peso a Desmama 31

4.1.3.2. Ganho de Peso da Desmama ao Sobreano 32

4.1.3.3. Peso ao Sobreano 33

4.1.3.4. Perímetro Escrotal 34

4.1.3.5. Altura 35

3.1.4. Escores Visuais $\quad 35$

$\begin{array}{ll}\text { 4.1.4.1. Musculosidade } & 35\end{array}$

4.1.4.2. Conformação 36

$\begin{array}{ll}\text { 4.1.4.3. Precocidade } & 37\end{array}$

3.2. Correlações Genéticas $\quad 38$

3.2.1. Correlações Genéticas de AOL com Característica de Desenvolvimento Ponderal

3.2.2. Correlações Genéticas de AOL com Escores

Visuais

40

3.2.3. Correlações Genéticas de EGS com Característica de Desenvolvimento Ponderal

42

3.2.4. Correlações Genéticas de EGS com Escores Visuais

44

3.2.5. Correlação Genética de EGS e AOL 45

5. Conclusões 46

6. REFERÊNCIAS BIBLIOGRÁFICAS 47 


\section{LISTA DE FIGURAS}

Figura 1 - Curva de crescimento de diferentes tipos fisiológicos. 2

Figura 2 - Aparelho Piemedical Scanner 200 VET. 14

$\begin{array}{lll}\text { Figura } 3 \text { - Transdutor de 3,5 MHz. } & 14\end{array}$

$\begin{array}{ll}\text { Figura } 4 \text { - Local da medida. } & \mathbf{1 5}\end{array}$

Figura 5 - Animal sendo preparado para a medida de ultra-som. 15

Figura 6 - Medida de área de olho de lombo. 16

$\begin{array}{lll}\text { Figura } 7 & \text { - Imagem gerada de AOL. } & 16\end{array}$

$\begin{array}{lll}\text { Figura } 8 & \text { - Medida de espessura de gordura subcutânea. } & 17\end{array}$

$\begin{array}{lll}\text { Figura } 9 & \text { - Imagem gerada de EGS. } & 17\end{array}$

Figura 10 - Proporções da variância total devida aos efeitos genéticos aditivos diretos $\left(\mathrm{h}^{2}\right)$ e efeitos residuais $\left(\mathrm{e}^{2}\right)$ para área de olho de lombo (obtidas em análises uni-característica).

Figura 11 - Comparação da variação das estimativas de herdabilidade de AOL obtidas em análise uni e bi-características no rebanho 1.26

Figura 12 - Comparação da variação das estimativas de herdabilidade de AOL obtidas em análises uni e bi-características no rebanho 2. 27

Figura 13 - Proporções da variância total devida aos efeitos genéticos aditivos diretos $\left(\mathrm{h}^{2}\right)$ e efeitos residuais $\left(\mathrm{e}^{2}\right)$ para espessura de gordura subcutânea (estimados em análises uni-característica). 28 
Figura 14 - Distribuição de medidas de EGS do rebanho 1 distribuído em classes de medidas

Figura 15 - Comparação da variação das estimativas de herdabilidade de EGS realizada em análise uni e bi-características no rebanho 1.

Figura 16 - Comparação da variação das estimativas de herdabilidade de EGS obtida em análise uni e bi-características no rebanho 2.

Figura 17 - Proporções da variância total devida aos efeitos genéticos aditivos diretos $\left(h_{a}^{2}\right)$, materno $\left(h_{m}^{2}\right)$, ambiente permanente da vaca $\left(c^{2}\right)$ e efeitos residuais $\left(\mathrm{e}^{2}\right)$ para peso a desmama (estimados em análises uni-característica).

Figura 18 - Proporções da variância total devida aos efeitos genéticos aditivos diretos $\left(\mathrm{h}^{2}\right)$ e efeitos residuais $\left(\mathrm{e}^{2}\right)$ para ganho de peso da desmama ao sobreano (estimados em análises unicaracterística).

Figura 19 - Proporções da variância total devida aos efeitos genéticos aditivos diretos $\left(\mathrm{h}^{2}\right)$ e efeitos residuais $\left(\mathrm{e}^{2}\right)$ peso ao sobreano (estimados em análises uni-característica).

Figura 20 - Proporções da variância total devida aos efeitos genéticos aditivos diretos $\left(\mathrm{h}^{2}\right)$ e efeitos residuais $\left(\mathrm{e}^{2}\right)$ para perímetro escrotal (estimados em análises uni-característica).

Figura 21 - Proporções da variância total devida aos efeitos genéticos aditivos diretos $\left(\mathrm{h}^{2}\right)$ e efeitos residuais $\left(\mathrm{e}^{2}\right)$ para altura (estimados em análises uni-característica).

Figura 22 - Proporções da variância total devida aos efeitos genéticos aditivos diretos $\left(\mathrm{h}^{2}\right)$ e efeitos residuais $\left(\mathrm{e}^{2}\right)$ para musculosidade (estimados em análises uni-característica).

Figura 23 - Proporções da variância total devida aos efeitos genéticos aditivos diretos $\left(\mathrm{h}^{2}\right)$ e efeitos residuais $\left(\mathrm{e}^{2}\right)$ para conformação (estimados em análises uni-característica). 
FIgURA 24 - Proporções da variância total devida aos efeitos genéticos aditivos diretos $\left(\mathrm{h}^{2}\right)$ e efeitos residuais $\left(\mathrm{e}^{2}\right)$ para precocidade (estimados em análises uni-característica).

FIgURA 25 - Correlações genéticas entre AOL e características de desenvolvimento ponderal para o rebanho 1

Figura 26 - Correlações genéticas entre AOL e características de desenvolvimento ponderal para o rebanho 2

Figura 27 - Correlações genéticas entre AOL e escores visuais para o rebanho 1.

Figura 28 - Correlações genéticas entre EGS e características de desenvolvimento ponderal para o rebanho 1

Figura 29 - Correlações genéticas entre EGS e características de desenvolvimento ponderal para o rebanho 2.

Figura 30 - Correlações genéticas entre EGS e escores visuais para o rebanho 1.

FIgURA 31 - Correlações genéticas entre EGS e AOL para o rebanho 1 e 2. 45 


\section{LISTA DE TABELAS}

Tabela 1 Medidas de desempenho e avaliação de caraça de 42 animais abatidos com peso médio de $453 \mathrm{Kg}$ (Adaptado de STRASIA et al., 1989).

Tabela 2 Resposta à seleção $(\Delta)$ sob um cenário de seleção típica (Adaptado de SHEPARD et al., 1996).

Tabela 3 Resposta à seleção baseada em características de medidas de ultrasom a uma idade e peso constante (Adapto de JOHNSON et al. 1993).

Tabela 4 Número de observações ( $\mathrm{N}^{\mathrm{o}}$ obs), número de grupos contemporâneos para cada característica ( $\left.\mathrm{N}^{\circ} \mathrm{GC}\right)$, média das características (Média), desvio padrão, coeficiente de variação (Coef. Var.), mínimo e máximo das características.

Tabela 5 Número de observações ( $\mathrm{N}^{\circ}$ obs), número de grupos contemporâneos para cada característica ( $\left.\mathrm{N}^{\circ} \mathrm{GC}\right)$, média das características (Média), desvio padrão, coeficiente de variação (Coef. Var.), mínimo e máximo das características.

Tabela 6 Número de observações ( $\mathrm{N}^{\mathrm{o}}$ obs), número de grupos contemporâneos para cada característica ( $\mathrm{N}^{\circ}$ GC), média das características (Média), desvio padrão, coeficiente de variação (Coef. Var.), mínimo e máximo das características.

Tabela 7 Freqüência das medidas de EGS.

Tabela 8 Classe das medidas de EGS. 


\section{Listas de Abreviaturas}

\begin{tabular}{|c|c|}
\hline ALT & - $\quad$ Altura \\
\hline AOL & - $\quad$ Área de olho de lombo \\
\hline AOLANO & - $\quad$ Área de olho de lombo medida com um ano de idade \\
\hline AOLDES & - $\quad$ Área de olho de lombo medida a desmama \\
\hline $\mathrm{C}$ & - Conformação \\
\hline C.V. & - Coeficiente de variação \\
\hline DP & - Desvio padrão \\
\hline EGS & - $\quad$ Espessura de gordura subcutânea \\
\hline EGSANO & - Espessura de gordura subcutânea medida com um ano de idade \\
\hline GC & - Grupo contemporâneo \\
\hline GP345 & - Ganho de peso da desmama ao sobreano \\
\hline M & - $\quad$ Média \\
\hline M & - Musculosidade \\
\hline MAX & - Máximo \\
\hline MIN & - Mínimo \\
\hline MTDFREML & - $\quad$ Multiple Trait Derivative Free Restricted Maximun Likelihood \\
\hline $\mathrm{N}$ & - $\quad$ Número de animais \\
\hline $\mathrm{P}$ & - $\quad$ Precocidade \\
\hline $\mathrm{PE}$ & - $\quad$ Perímetro escrotal \\
\hline PESDES & - $\quad$ Peso a desmama \\
\hline PESSOB & - $\quad$ Peso ao sobreano \\
\hline $\mathrm{SAS}^{\circledR}$ & - $\quad$ Statiscal Analysis System \\
\hline
\end{tabular}




\section{Lista de Símbolos}

$\begin{array}{ll}\sigma_{p}^{2} & - \text { Variância fenotípica } \\ \sigma_{p} & \text { - } \text { Desvio-padrão fenotípico } \\ \sigma_{a}^{2} & \text { - } \text { Variância genética aditiva } \\ \Delta G / g e n & - \text { Ganho genético por geração } \\ \Delta G / \text { ano } & \text { - } \text { Ganho genético por ano } \\ h^{2} & \text { - Estimativa do coeficiente de herdabilidade para os efeitos genéticos } \\ & \text { aditivos diretos } \\ h_{m}^{2} & \text { Estimativa do coeficiente de herdabilidade para os efeitos genéticos } \\ h_{a}^{2} & \text { - } \text { Estitivos maternos } \\ e^{2} & - \text { Fração da variância fenotípica devido aos efeitos residuais }\end{array}$




\section{Resumo}

FIGUEIREDO, L.G.G. Estimativa de parâmetros genéticos de características de carcaça feitas por ultra-sonografia em bovinos da raça Nelore. Pirassununga, 2001. 52p. Dissertação (mestrado) - Faculdade de Zootecnia e Engenharia de Alimentos, Universidade de São Paulo.

O presente trabalho teve como objetivo estimar parâmetros genéticos de características de carcaças feitas por ultra-sonografia em bovinos da raça Nelore bem como as suas correlações genéticas com características de desenvolvimento ponderal e com escores visuais. Os dados coletados pertencem a três fazendas, duas pertencentes a Agropecuária CFM (Rebanho 1) que foram analisadas em conjunto com 1696 animais e uma pertencente a Manah Agropastoril Ltda. com 951 animais (rebanho 2). As características analisadas foram: área de olho de lombo (AOL), espessura de gordura subcutânea (EGS), peso a desmama (PESDES), ganho de peso da desmama ao sobreano (GP345), peso ao sobreano (PESSOB) e altura (ALT). E os escores visuais analisados foram: musculosidade (MUSC), conformação (CONF) e precocidade (PREC). Os componentes de (co)variância foram estimados por verossimilhança restrita, utilizando-se o software MTDFREML. Foram realizadas análises uni-características em que foram estimadas as herdabilidades das características AOL e EGS e análises bi-características em que foram estimadass as correlações genéticas das características de AOL e EGS com as características de desempenho ponderal e escores visuais. As estimativas herdabilidades para AOL foram de 0,19 (rebanho 1) e de 0,41 (rebanho 2), para a EGS foram de 0,04 (rebanho 1) e de 0,19 (rebanho 2). Estas herdabilidades sugerem que as características são passíveis de seleção. São sugeridos estudos adicionais de estimativas de componentes de (co)variância para medidas de ultra-sonografia para bovinos da raça Nelore.

Palavras Chaves: ultra-sonografia, Nelore, parâmetros genéticos, carcaça, avaliação de carcaças in vivo 


\begin{abstract}
FIGUEIREDO, L.G.G. Genetic parameters for carcass traits measured trough ultrasound in Nelore cattle.
\end{abstract}

This research was conducted to estimate variance components and genetic parameters of carcass traits of Nelore cattle, measured through ultrasound equipment, and also the genetic relationship of those traits with growth traits and visual scores. Data came from three different herds. 1,696 animals were measured in two farms owned by AgroPecuaria CFM Ltda. (herd 1) and 951 animals were measured at Fazenda Mundo Novo, owned by Manah Agropastoril Ltda. (herd 2). The traits analyzed were: loin-eye are (AOL,

$\mathrm{cm}^{2}$ ), subcutaneous fat thickness (EGS, mm), weaning weight (PESDES, $\mathrm{kg}$ ), weight gain from weaning to yearling (GP345, kg), yearling weight (PESSOB, kg), and height (ALT, $\mathrm{cm}$ ). Visual scores were muscle score (MUSC), body conformation (CONF) e precocity (PREC). (Co)variance components were estimated by REML methods, using the software MTDFREML, under single traits (to estimate components for AOL and EGS) and twotraits analysis to estimate genetic correlations among AOL and EGS and the other traits. Heritability estimates for AOL were 0.19 (herd 1) and 0.41 (herd 2). While for EGS the values estimated were 0.04 (herd 1) and 0.19 (herd 2). The heritability coefficients estimated suggest that the traits can be selected. Further studies are suggested as related to (co)variance components estimation for ultrasound measurements in Nelore cattle.

Key words: ultrasound measurements, Nelore, genetic parameters, carcass traits, in vivo carcass evaluation 


\section{INTRODUÇÃo E REVISÃo BIBLIOGRÁFICA}

O rebanho bovino brasileiro é composto por cerca de 157 milhões de cabeças (ANUALPEC, 2000), sendo que 80\% tem alguma composição genética de zebu (Josahkian, 2000). Verifica-se também que a raça Nelore destaca-se em importância no rebanho nacional, com 31\% do sêmen comercializado no Brasil no ano de 1999, segundo a Associação Brasileira de Inseminação Artificial e 76\% dos registros genealógicos definitivo da ABCZ (Josahkian, 2000).

Segundo ANUALPEC (2000), em 1999 foram abatidas 31,6 milhões de cabeças, com uma produção de 6,5 milhões de toneladas de equivalente carcaça sendo assim o segundo produtor de carne bovina no mundo.

Com a tendência de diminuição do ciclo de produção e a maior demanda por carne

de melhor qualidade, há necessidade de alterar a forma da curva de crescimento do animal, para que se obtenha um animal com peso e acabamento adequados para o abate em uma idade cada vez mais jovem.

A curva de crescimento poderia ser alterada pela seleção para algumas características. Em relação às características de desempenho ponderal já existem programas bem definidos, mas no que se refere à qualidade e produtividade de carcaça, quase nada tem sido feito.

Para que se possa fazer uma eficiente seleção deve-se identificar características indicadoras da qualidade e produtividade de carcaça. Entre esta, a espessura de gordura subcutânea e a área do músculo Longissimus Dorsi ou área de olho de lombo. 
A espessura de gordura de subcutânea tem grande importância na industrialização da carne, sendo fundamental no processo de resfriamento da carcaça. O resfriamento deve ser feito de forma lenta e gradual para não causar encurtamento das fibras e, por conseguinte o endurecimento da carne. A falta de gordura de cobertura permite a uma perda excessiva de água ocasionando, além da perda de peso, o escurecimento da carne durante o período de resfriamento. A conseqüência é a diminuição do peso dos cortes comerciais e menor qualidade da carne.

Segundo Wilson (1992), a porcentagem de gordura subcutânea tem uma correlação alta e positiva com porcentagem de gordura de recorte e negativa com porcentagem de carne magra na carcaça. A utilização da espessura de gordura subcutânea como ponto de referência para classificar animais in vivo para o abate seria uma técnica recomendável.

Segundo Luz_e_Silva (1995), citando Berg e Buterfield (1979), a gordura é um tecido de deposição tardia em relação a outros tecidos corpóreos e, geralmente, bovinos de raças mais precoces têm um menor tamanho e começam a deposição de gordura subcutânea a um peso menor com demonstra a Figura 1.

Figura 1: Curva de crescimento de diferentes tipos fisiológicos

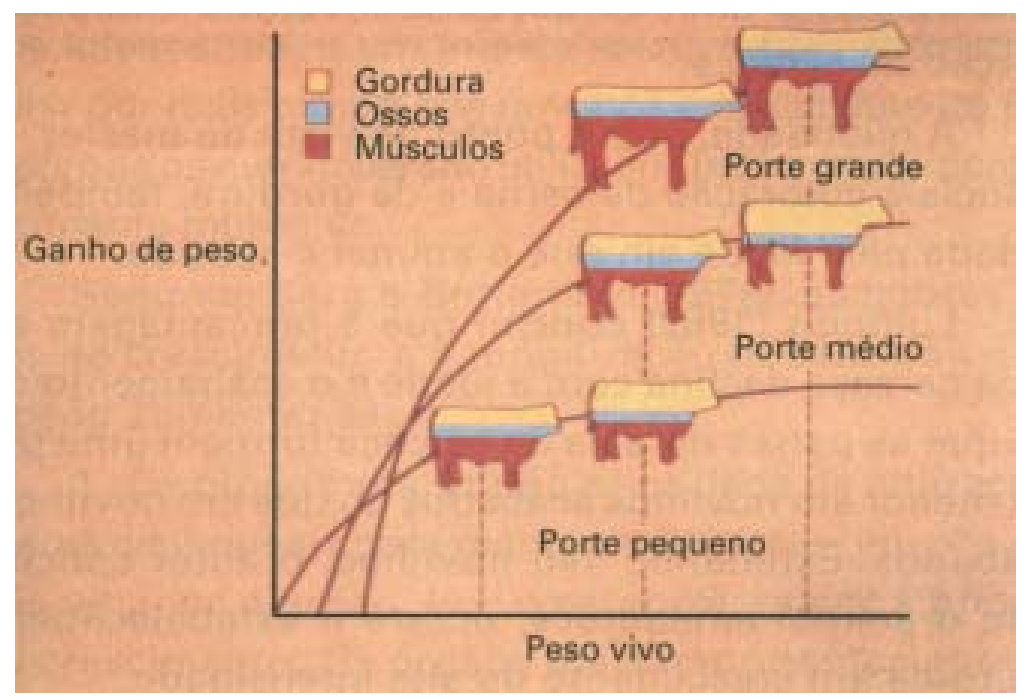

Fonte: Luchiari Filho (2000)

Fundamentando-se nesta premissa pode-se identificar animais fisiologicamente mais precoces dentro de um lote, pela medição da espessura de gordura subcutânea.

Segundo Boggs e Merkel (1990) e Luchiari Filho (2000), a área de olho de lombo (AOL), medida na entre a $12^{\circ}$ e $13^{\circ}$ costelas é utilizada como indicador de 
composição de carcaça. Esta medida tem sido relacionada à musculosidade e como indicador de rendimento dos cortes de alto valor comercial. Luchiari Filho (2000), relata também que esta característica tem uma correlação positiva com a porção comestível da carcaça.

Atualmente pode-se obter se obtém estas informações através da avaliação das carcaças ou em animais vivos.

Embora a obtenção dessas medidas em animais abatidos, seja uma alternativa razoável e contribua em grande parte para a formação dos bancos dados atualmente utilizados em programas de melhoramento genético, ela apresenta dois grandes problemas:

- O primeiro é que o método requer um teste de progênie no qual os animais devem ser abatidos. O teste de progênie é um eficiente método de se predizer o mérito genético, mas é dispendioso e demanda longos períodos de tempo;

- O segundo problema é que a coleta de dados tem de ocorrer em locais apropriados (frigoríficos) e exige uma cooperação íntima entre quem faz a coleta e quem utiliza os dados para a avaliação genética. Este procedimento também introduz uma fonte de erros, pois uma falha na transferência de um dos dados pode prejudicar o processo por inteiro. Os erros são difíceis de serem detectados e quando detectados, nem sempre podem ser corrigidos.

Estes dois problemas relacionados às medidas de carcaças de animais abatidos, mais o fato de os criadores não serem remunerados pelo mérito destas carcaças, respondem pela ausência de programas de avaliação desta característica na indústria (Wilson, 1992).

Uma alternativa ao método direto seria obtenção de medidas em animais vivos, o que pode ser feito de várias formas como, por exemplo, medidas de escores corporais, medidas feitas com o uso de equipamentos de ressonância magnética e ultra-sonografia.

O método de avaliação de animais através de escore corporal é prático, mas por ser subjetivo, depende muito do treinamento dos técnicos envolvidos para que se obtenham bons níveis de confiabilidade. Segundo Koury Filho et al. (2000), para que 
haja uma maior credibilidade e validade do uso de tal metodologia, é necessária a realização de encontros técnicos dos profissionais envolvidos para chegar-se a um consenso sobre a de avaliar e de padronizar as características.

A medida através de ressonância magnética seria a mais exata, mas o custo do equipamento e a impossibilidade de trabalhar com ele à campo tornam impraticável sua utilização.

A ultra-sonografia é um método mais simples e que fornece boa confiabilidade aliada a praticidade em trabalhos a campo.

Há vários tipos de aparelhos de ultra-som no mercado, mas todos operam com o princípio de ondas sonoras enviadas criando um eco quando bate em uma superfície densa. O som é uma onda mecânica de compressão e refração por um meio. Uma onda sonora pode ser comparada a uma onda longitudinal que possui freqüência e velocidade. O comprimento de onda é à distância entre dois pontos iguais em uma determinada onda. Freqüência é o número de ciclos em um determinado período de tempo. A velocidade deriva da freqüência e comprimento; a velocidade da onda varia viajando mais rápido pela gordura que pela carne, devido à diferença de densidades.

Sabendo-se a freqüência e a velocidade, o comprimento de onda pode ser calculado. Devido à velocidade do som em um dado tecido ser constante, mudando a freqüência, mudará o comprimento de onda. Isso irá, por sua vez, afetar a resolução e qualidade da imagem produzida pelo ultra-som. O diagnóstico do ultra-som é produzido por cristais da unidade transmissora com propriedades de pressão elétrica. Quando os cristais são deformados pela pressão, produzem eletricidade. Inverso a isso, quando uma corrente elétrica é aplicada, os cristais se deformam. Este é o processo pelo qual a onda sonora é gerada e recebida pelo transdutor. Quando refletido, o som retorna e uma deformação leve nos cristais é produzida; isso gera uma corrente elétrica. A corrente aparece num osciloscópio como uma imagem das interfaces do tecido.

Segundo Saviani (1993), a diferença de velocidade existente nos principais tecidos moles é a base técnica para estimações in vivo da composição de carcaça e medições de tecidos. 
Um limite tênue entre os tecidos, como a faixa entre a gordura subcutânea e o músculo, resulta numa reflexão especular de som qual; produz uma imagem congruente no monitor.

Tecidos que contém colágeno causam dispersões acústicas (Fellingham \& Sommer, 1984 citado por Barros, 1993). As interferências construtiva e destrutiva vindas das diferenças de fase entre as cristas das ondas de várias dispersões produzem granulações e contrastes aleatórios nas imagens do ultra-som, as quais são ditas dispersões (Magnim, 1983 citado por Barros, 1993).

Há três tipos de aparelhos de ultra-sonografia. O primeiro é chamado de método de amplitude ou método "A”, no qual o aparelho ultra-som apresenta uma imagem uni direcional da amplitude e distância do retorno do eco. O segundo, é o método do brilho ou método “B”, onde há duas exibições de pontos dimensionais. O transdutor é movido através da superfície e é apresentada uma imagem de um corte anatômico seccional. O terceiro é o método do movimento do ultra-som ou "M" ou “MT-mode”, é um formato unidimensional que descreve pontos ou pequenos sinais, apoia-se o transdutor em um lugar sobre os órgãos em movimento. Este é mais usado em ecocardiogramas.

Segundo El Faro (1993), os métodos utilizados para escaneamento de bovinos de corte são os tipos “A” e “B”.

Para medições que não necessitem de grande precisão pode ser usado um aparelho de ultra-som do tipo "A” que é de fácil manuseio e baixo custo, mas para medidas mais acuradas, como as necessárias para um banco de dados de um programa de melhoramento, se recomenda o uso de aparelhos de ultra-som do tipo “B”. Estes aparelhos além de mais acurados em suas medidas fornecem a possibilidade de armazenagem de imagem para posterior análise em programas computacionais com maior precisão.

A medição de animais vivos por ultra-sonografia tem como objetivo a predição das diferenças genéticas entre os indivíduos e a identificação de reprodutores geneticamente superiores.

A ultra-sonografia é usada, basicamente, para quatro finalidades dentro das técnicas de avaliação in vivo de carcaças: 
- avaliação da composição corporal dos reprodutores (machos e fêmeas) e de seus descendentes;

- monitoração da composição corporal da população comercial: avaliação dos lotes (grupos contemporâneos), quanto à deposição de gordura, por exemplo, para fins de determinação do momento ótimo de abate;

- seleção, na fazenda, do gado para mercado e abate: o ultra-som torna-se uma ferramenta extra para auxiliar no processo de seleção/descarte no rebanho;

- valorização do gado comercial no mercado, em particular no mercado de leilões, valorização de lotes e de reprodutores com características positivas para rendimento de carcaça (deposição de gordura em níveis aceitáveis) (Barros, 1993).

O uso da ultra-sonografia já esta sendo comprovada por diversos autores como, Perkins et al. (1992) que, realizaram medidas de ultra-som na região da $12^{\circ}$ $13^{\circ}$ costelas de 495 machos cruzados confinados e 151 novilhas 24 horas antes do abate com o objetivo de avaliar a acurácia das medidas de ultra-som para espessura de gordura e área de olho de lombo na predição de medidas reais destas características nas carcaças. A conclusão foi de que medidas de espessura de gordura e área de olho de lombo, feitas por ultra-som antes do abate podem ser preditores relativamente acurados das medidas reais na carcaça em gado de corte.

Brethour (1992), determinou a repetibilidade de medidas de espessura de gordura pelo ultra-som em 217 animais e a associação de medidas de carcaça e ultrasom foi avaliada com 580 animais. Este autor concluiu que medidas de ultra-som podem ser mais precisas e acuradas que medidas de carcaça para avaliar a espessura de gordura em gado de corte.

Robinson et al. (1992), fizeram a avaliação de medidas de carcaça em animais vivos por ultra-som e da acurácia dos operadores do aparelho. Os resultados encontrados confirmam a acurácia da medida de ultra-som sua efetividade na predição de medida de carcaça e seu uso potencial em programas de seleção.

Renand \& Fisher (1997) compararam quatro métodos de avaliação de carcaças e concluíram que medidas de ultra-som são mais eficientes para predição de gordura nas carcaças dos animais. 
Robinson et al (1998) verificaram, em animais comerciais que foram inseminados com touros testados para características de carcaça medidas através de ultra-som que as características se refletem na desempenho de carcaça das progênies.

Baleiy et al. (1986), estudando 260 bovinos cruzados separados em 3 categorias de peso (340, 470 e $600 \mathrm{~kg}$ ) encontraram correlações significativas entre medidas de ultra-som e algumas características de composição de carcaça. No citado estudo, geralmente havia pouca diferença nos coeficientes de correlação múltipla e erros-padrão de estimativas, com ou sem a inclusão de medidas de ultra-som, em relação às outras medidas “in vivo”. As máximas correlações múltiplas para porcentagem de gordura na carcaça, carne magra e cortes nobres, usando todas as medidas “in vivo", foram de 60 a $70 \%$.

Smith et al. (1989b) estudando 96 animais a um ano de idade, divididos em três classes de peso inicial (300, 365, 395 kg), de vários tipos raciais e abatidos em duas etapas (animais com 365 e $395 \mathrm{~kg}$ de peso inicial formaram o grupo 1 de abatidos e os animais com $300 \mathrm{~kg}$, o grupo 2), anotaram medidas subjetivas (condição, musculosidade) e medidas de ultra-som (espessura de gordura subcutânea - EGS - e área de olho de lombo - AOL) para estimar ganho médio diário, área de olho de lombo, espessura de gordura, marmorização e classe de rendimento de carcaça. A maior parte da variação é explicada pela combinação de raça, peso inicial e dados de ultra-som, quando comparada à avaliação subjetiva sugerindo que as medições ultrassônicas de EGS e AOL iniciais podem ser úteis como ferramentas para melhorar a capacidade de predição de uma série de parâmetros de carcaças. E também, que as medições em ultra-som da EGS podem ser úteis na identificação de animais com potencial ganho compensatório ou potencial para aumentar o tamanho corporal e o crescimento.

Aos 110 dias de um experimento, Strasia et al. (1989) mensuraram com ultrasom 123 novilhas para medir a espessura de gordura subcutânea (EGS). Cerca de 42 animais, com peso de $453 \mathrm{~kg}$ e EGS de $12,7 \mathrm{~mm}$, foram abatidos e o EGS real foi medido. Os animais remanescentes foram abatidos aos 145 dias do experimento. Alguns resultados encontrados pelos pesquisadores estão na Tabela 1. 
Tabela 1: Medidas de desempenho e avaliação de caraça de 42 animais abatidos com peso médio de $453 \mathrm{Kg}$ (Adaptado de Strasia et al., 1989).

\begin{tabular}{ccc}
\hline Medida & Dia do abate * & Valor \\
\hline Ganho de Peso diário, g & 110 dias de experimento & 1279 \\
2.1 Peso da Carcaça, $k g$ & 145 dias de experimento & 1111 \\
Área de Olho de Lombo, cm ${ }^{2}$ & 110 dias de experimento & 284 \\
& 145 dias de experimento & 278,5 \\
Escore de Marmorização & 110 dias de experimento & 76,8 \\
& 145 dias de experimento & 76,8 \\
& 110 dias de experimento & 397 \\
Classificação da Carcaça (quanto ao rendimento) & 110 dias de experimento & 2,73 \\
& 145 dias de experimento & 2,76 \\
\hline
\end{tabular}

* As medidas aos 110 dias foram obtidas por pesagem e avaliação através de ultra-som, as de 145 dias foram obtidas nas carcaças.

Shepard et al. (1996) estimaram os parâmetros genéticos para as medidas de área de olho de lombo (AOL) e espessura de gordura subcutânea (EGS) feitas por ultra-som em 805 touros e 877 novilha da raça Angus incluindo nas análises informações adicionais de peso a desmama (PESDES), peso pós-desmama (PPDES) e circunferência escrotal (PE). Verificando que a seleção para a EGS e AOL é possível como demonstra a Tabela 2. 
Tabela 2: Resposta à seleção $(\Delta)$ sob um cenário de seleção típica ${ }^{\mathrm{a}}$, (Adaptado de Shepard et al., 1996).

\begin{tabular}{|c|c|c|c|c|c|c|}
\hline Característica $^{\mathrm{b}}$ & $h^{2}$ & $\sigma_{\mathrm{p}}$ & $\Delta /$ ano & $\begin{array}{c}\text { \% } \Delta \text { para } \\
\text { média } \\
\text { (após } 1 \text { ger. }{ }^{\mathrm{c}} \text { ). }\end{array}$ & $\begin{array}{c}\text { Correlação } \\
\text { de } \Delta / \text { ano e } \\
\text { PESDES } \\
\text { (direta) }\end{array}$ & $\begin{array}{c}\text { Correlação } \\
\text { De } \Delta / \text { ano e } \\
\text { PESDES } \\
\text { (materna) }\end{array}$ \\
\hline EGS, cm & 0.56 & 0.1714 & $\begin{array}{l}0.022 \\
8\end{array}$ & 16.3 & 0.1402 & -0.571 \\
\hline $\begin{array}{r}\text { AOL, } \mathrm{cm}^{2} \\
\text { PESDES } \\
\text { direta, kg }\end{array}$ & $\begin{array}{l}0.11 \\
0.20\end{array}$ & $\begin{array}{l}7.73 \\
28.69\end{array}$ & $\begin{array}{r}0.435 \\
1.83\end{array}$ & $\begin{array}{l}2.80 \\
2.98\end{array}$ & 0.2019 & 0.0055 \\
\hline
\end{tabular}

${ }^{\text {a} C e n a ́ r i o ~ d e ~ s e l e c ̧ a ̃ o: ~ 5 \% ~ d o s ~ m e l h o r e s ~ t o u r o s ~ s e l e c i o n a d o s, ~ 50 \% ~ d a s ~ m e l h o r e s ~ v a c a s ~ s e l e c i o n a d a s, ~ s e l e c i o n a d o s ~}$ com base nos valores individuais, fêmeas e machos têm um intervalo médio de geração de 4,5 anos.

${ }^{\mathrm{b}} \mathrm{EGS}$ = espessura de gordura subcutânea, AOL= área de olho de lombo e PESDES= peso a desmama.

'ger. = geração

Johnson et al., (1993) estudando 2.101 Brangus nascidos de 1986 a 1990 estimaram pelo método de máxima verossimilhança restrita (REML), parâmetros genéticos para medidas de ultra-som de área de olho de lombo e espessura de gordura na $12^{\mathrm{a}}$ costela, medidas a uma idade e um peso constante. Os resultados alcançados com a seleção feita através do uso de medidas ultrassônicas a uma idade constante teria um ganho um pouco maior que seleção feita através de medidas utrassônicas a um peso constante, como demonstra a Tabela 3. 
Tabela 3: Resposta à seleção baseada em características de medidas de ultra-som a uma idade e peso constante (Adaptado de Johnson et al., 1993).

\begin{tabular}{|c|c|c|c|c|}
\hline Característica & $\mathbf{h}_{\mathbf{a}}^{2}$ & $\sigma_{a}^{2}$ & $\Delta$ G/gen. $^{\mathrm{b}}$ & $\Delta \mathrm{G} / \mathrm{ano}^{\mathrm{c}}$ \\
\hline \multicolumn{5}{|l|}{ Idade Constante } \\
\hline AOLDES, $\mathrm{cm}^{2}$ & 0.39 & 6.15 & 3.43 & 0.86 \\
\hline AOLANO, $\mathrm{cm}^{2}$ & 0.40 & 7.39 & 4.23 & 1.06 \\
\hline EGSANO, cm & 0.14 & 0.094 & 0.019 & 0.005 \\
\hline \multicolumn{5}{|l|}{ Peso Constante } \\
\hline AOLDES, $\mathrm{cm}^{2}$ & 0.36 & 4.99 & 2.57 & 0.64 \\
\hline AOLANO, $\mathrm{cm}^{2}$ & 0.39 & 6.70 & 3.74 & 0.94 \\
\hline EGSANO, cm & 0.11 & 0.090 & 0.014 & 0.004 \\
\hline \multicolumn{5}{|c|}{$\begin{array}{l}{ }^{\text {aAOLDES }} \text { = medida de ultra-som da área de olho de lombo a desmama, AOLANO = medida } \\
\text { de ultra-som da área de olho de lombo a um ano de idade e EGSANO = medida de ultra-som da } \\
\text { espessura de gordura a um ano de idade }\end{array}$} \\
\hline \multicolumn{5}{|c|}{$\begin{array}{l}{ }^{b} \Delta G / \text { gen. = ganho genético por geração }=1 / 2\left(i_{m}+i_{f}\right) \cdot h_{a}^{2} \cdot \sigma_{p}, \text { para } i_{m}=\text { intensidade de } \\
\text { seleção para machos }=2,06 ; i_{\mathrm{f}}=\text { intensidade de seleção para fêmeas }=0,80 ; h_{a}^{2}=\end{array}$} \\
\hline
\end{tabular}

Segundo Bang et al. (1994), a correlação existente entre peso corporal do animal vivo e a espessura de gordura subcutânea, medida com ultra-som, foi de 0,78 para 42 touros pesando entre 260 e 650 kg. Esta mesma correlação, na carcaça, foi de 0,77, demonstrando a utilidade da medida de ultra-som.

Waldner et al. (1992) citado por Johnson et al. (1993), informaram que medidas de ultra-som de "real-time" de área de olho de lombo ajustadas para 12 meses e de espessura de gordura ajustada para 12 ou 16 meses por técnicos qualificados foram precisas o bastante para caracterizar grupos de animais. Eles indicaram que estas medidas poderiam ser usadas com outras medidas dos animais, como peso ou altura de garupa, para identificar animais jovens com composição genética superior. A seleção baseada em características medidas por ultra-som em gado jovem poderia permitir mais rapidamente o progresso genético e econômico. Porém, antes que características medidas por ultra-som sejam usadas em programas de seleção de gado de corte, é preciso estimar os seus componentes de variância e covariância. 
Lôbo et al. (2000), ao revisarem parâmetros genéticos encontraram em média 0,30 de herdabilidade para o peso a desmama, 0,31 para peso ao sobreano de e 0,31 para perímetro escrotal.

Na raça Nelore Eler et al. (1996), relatam as seguintes herdabilidades para peso a desmama ajustado para 205 dias de idade: 0,29 para efeito direto 0,08 para efeito materno, para peso ao sobreano ajustado aos 550 dias de idade a herdabilidade de 0,30 e para perímetro escrotal de 0,52.0 mesmo autor também descreve que os escores são valores atribuídos numa escala de 1 (péssimo) a 9 (excelente). O escore de conformação considera o comprimento, a largura, a profundidade e a aparência geral do animal. A precocidade é uma medida da capacidade do indivíduo em armazenar reservas de gordura, indicando ser mais precoce em sua terminação. A musculosidade leva em conta a massa muscular presente no animal, neste estudo os autores encontraram as seguintes herdabilidades para estas avaliações, 0,34 para conformação, 0,29 para precocidade e 0,33 para musculosidade. 


\section{ObJetivo}

Os objetivos do presente trabalho são:

1. Obter informações sobre a espessura de gordura subcutânea (EGS) e área de olho de lombo (AOL) em bovinos da raça Nelore, utilizando tecnologia de ultra-som com scanner "real-time” bidimensional;

2. Estimar componentes de variância e covariância para as características citadas, utilizando a metodologia de modelos mistos (modelo animal), em análise simultânea de várias características, utilizando o peso a desmama como característica âncora e todas as informações disponíveis da genealogia dos animais;

3. Estimar correlações genéticas entre as medidas de ultra-som (AOL e EGS) as características de desenvolvimento ponderal (peso desmama (PD), peso ao sobreano (P550), ganho de peso da desmama ao sobreano (GP345)), escores visuais (musculosidade (MUSC), conformação (CONF), precocidade (PREC)), perímetro escrotal (PE);

4. Estimar as diferenças esperadas de progênie para EGS, AOL; 


\section{Material e Métodos}

\subsection{Local da Colmeita de Dados}

O dados foram obtidos nas fazendas São Francisco (Magda, SP), Cherubim (Américo de Campos, SP) (Rebanho 1) e Mundo Novo do grupo Manah (Brotas, SP) (Rebanho 2). Uma descrição dos dados é apresentada na Tabela 4.

Na fazenda São Francisco, as medidas foram feitas de 05/07/1999 a 15/07/1999. Na fazenda Cherubim, 16/07/1999 à 20/07/1999 enquanto na fazenda Mundo Novo foi de 7/09/1999 à 08/07/1999. Apenas machos da raça Nelore foram medidos.

Tabela 4: Número de observações (N), Média (M), Desvio-padrão (PD), Mínimo (MIN), Máximo (MAX) das medidas de ultra-som da Fazenda São Francisco.

\begin{tabular}{|c|c|c|c|c|c|c|}
\hline Fazendas & Variável & $\mathrm{N}$ & $2.2 \mathrm{M}$ & $\mathrm{DP}$ & MIN & MAX \\
\hline \multirow{3}{*}{ São Francisco } & $\mathrm{AOL}\left(\mathrm{cm}^{2}\right)$ & 1.080 & 43,02 & 6,1 & 25,48 & 65,07 \\
\hline & EGS (mm) & 1.080 & 2,74 & 0,8 & 0,60 & 5,10 \\
\hline & Idade à medição (dias) & 1.080 & 658,10 & 65,2 & 586,00 & 922,00 \\
\hline \multirow{3}{*}{ Cherubim } & $\mathrm{AOL}\left(\mathrm{cm}^{2}\right)$ & 616 & 41,77 & 5,4 & 30,24 & 65,700 \\
\hline & EGS (mm) & 616 & 1,81 & 0,6 & 0,00 & 4,00 \\
\hline & Idade à medição (dias) & 616 & 685,30 & 75,3 & 597,00 & 930,00 \\
\hline \multirow{3}{*}{ Mundo Novo } & $\mathrm{AOL}\left(\mathrm{cm}^{2}\right)$ & 368 & 43,76 & 5,25 & 29,93 & 58,52 \\
\hline & EGS (mm) & 368 & 2,08 & 0,60 & 0,00 & 4,00 \\
\hline & Idade à medição (dias) & 368 & 639,11 & 54,70 & 560 & 920 \\
\hline
\end{tabular}




\subsection{EQUIPAMENTO}

As informações de área de olho de lombo (AOL) e espessura de gordura subcutânea (EGS) foram coletadas em animais vivos sendo feita uma coleta por animal. O aparelho utilizado foi um Piemedical Scanner 200 VET (Figura 2) e com um transdutor linear de 3,5 MHz com $18 \mathrm{~cm}$ (Figura 3).

\subsubsection{Aparelho}

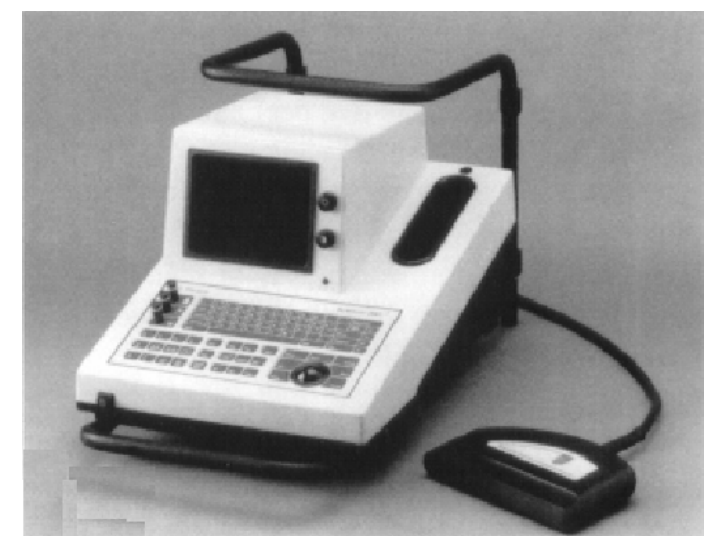

Figura 2 - Aparelho Piemedical Scanner 200 VET.

\subsubsection{Transdutor}

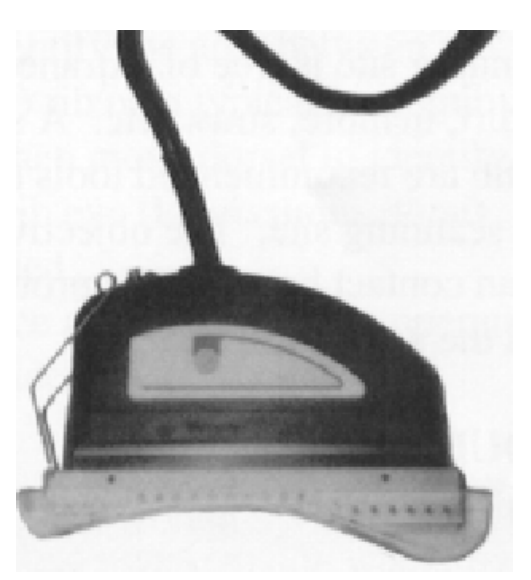

Figura 3 - Transdutor de 3,5 MHz. 


\subsection{LOCAL DA MEDIÇÃO POR ULTRA-SONOGRAFIA}

A coleta de dados foi realizada entre a $12^{\circ}$ e $13^{\circ}$ costelas, como mostra a Figura 4.

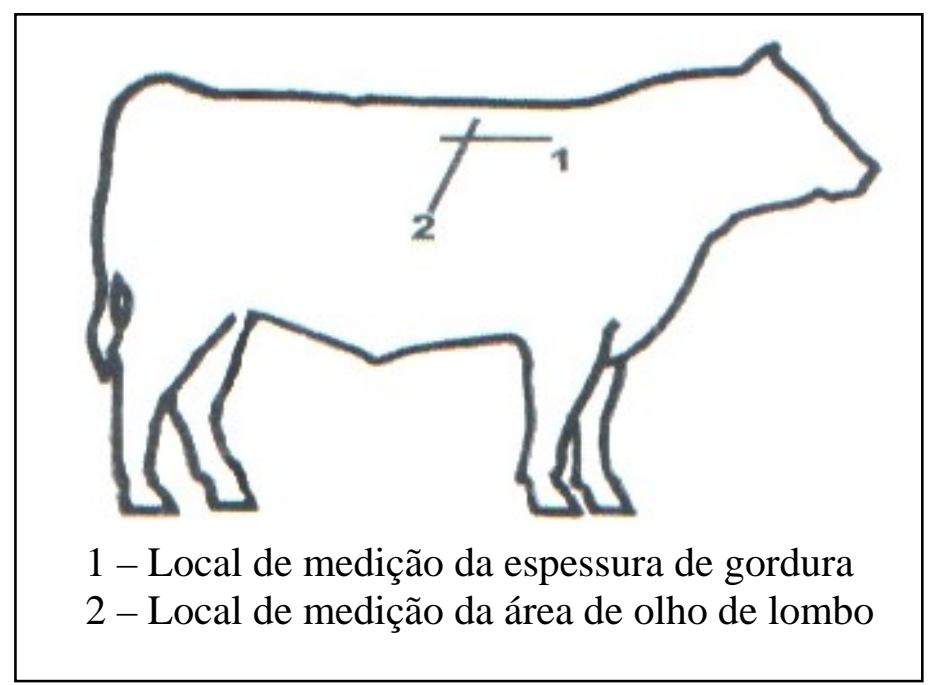

Figura 4 - Local de medição.

\subsection{Procedimento de Coleta}

O animal foi contido e o local de coleta de imagens foi preparado como na Figura 5.

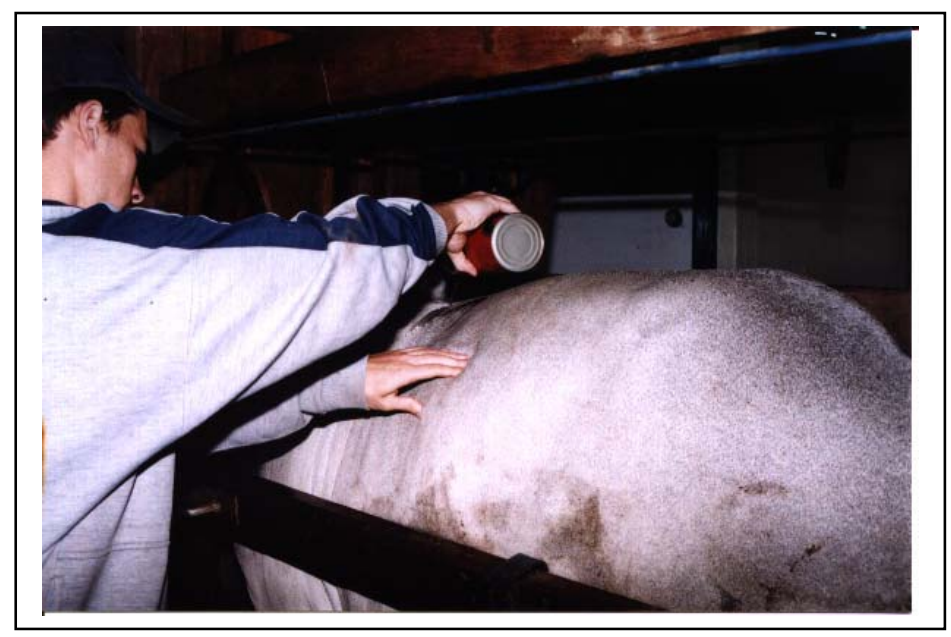

Figura 5 - Animal sendo preparado para a medição por ultra-som. 
A primeira medição realizada foi a de AOL. Para isto, o transdutor (probe) foi colocado transversalmente ao animal no espaço entre a $12^{\mathrm{a}}$ e a $13^{\mathrm{a}}$ costelas (Figura 6) gerando assim a imagem apresentada na Figura 7.



Figura 6 - Medição de área de olho de lombo.

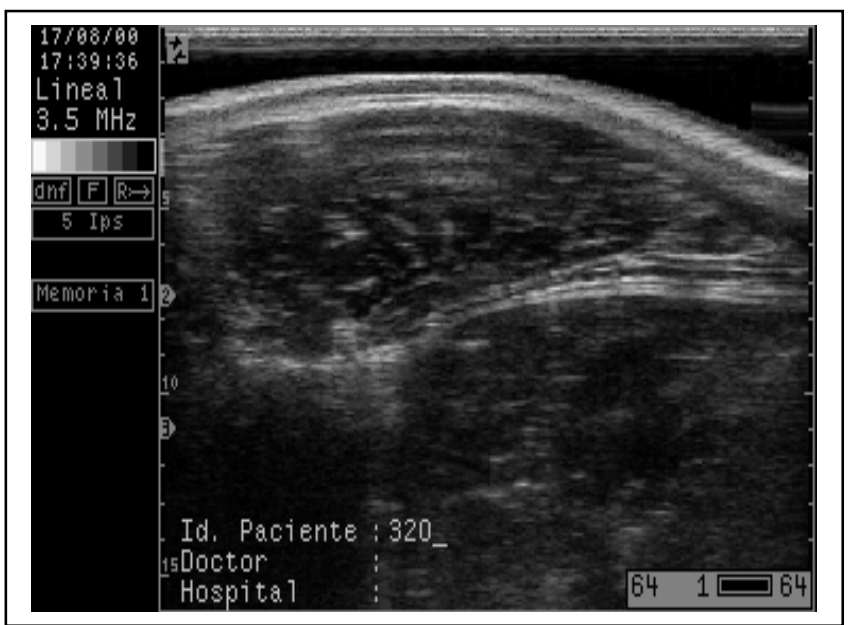

Figura 7 - Imagem gerada de AOL

A segunda medição foi de EGS, o transdutor foi colocado paralelamente à espinha dorsal do animal (Figura 8) gerando a imagem apresentada na Figura 9, na qual se localiza a $12^{\mathrm{a}}$ e $13^{\mathrm{a}}$ costelas para realizar a medição de EGS. 


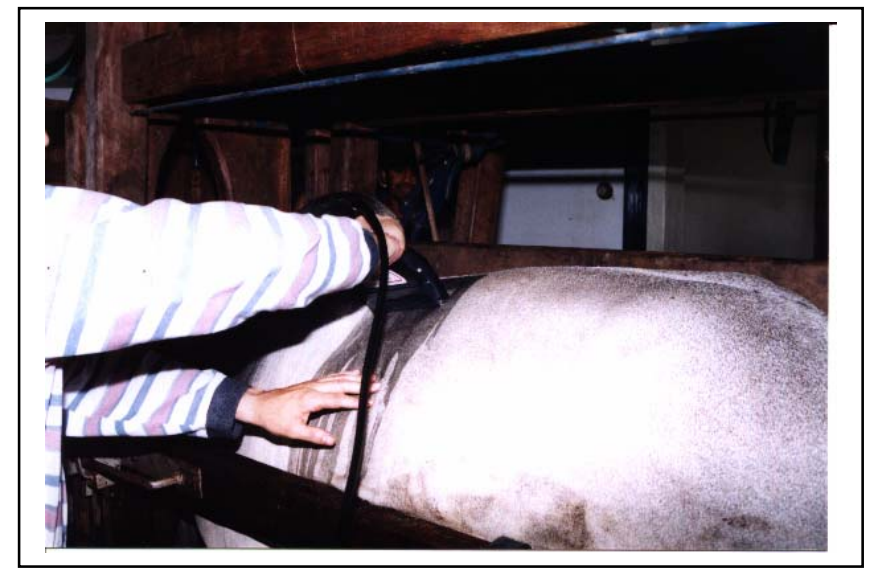

Figura 8 - Medida de espessura de gordura subcutânea.

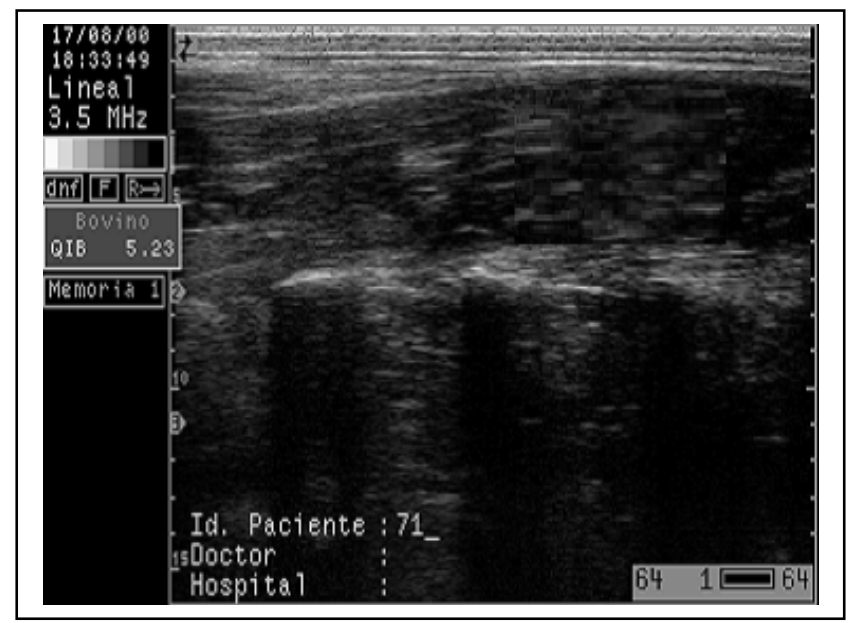

Figura 9 - Imagem gerada de EGS.

\subsection{FORMAÇÃo DO BANCO DE DADOS}

\subsubsection{FAZENDAS SÃo Francisco e CHERUbiM (REBANHo 1)}

A digitação e consistência dos dados foram feitas utilizando-se o software FOXPRO 2.6 da Microsoft. Com esses dados formou-se o arquivo de dados das Fazendas São Francisco e Cherubim que irá ser utilizado para as análises preliminares em SAS e posteriormente nas análises em MTDFREML. Neste arquivo constam todas as características de produtividade e escores visuais de conformação (C), Precocidade (P) e musculosidade (M) além das medidas de AOL e EGS dos 
animais coletados. No mesmo arquivo encontram-se as informações de idades à medição e/ou pesagem. Foram incluídos no arquivo não somente os animais que apresentam as informações de AOL e EGS, mas todos os meio-irmãos e irmãos completos totalizando um montante de 28.091 animais no arquivo, gerando um arquivo de pedigree com 53.096 animais. As médias dos dados das duas fazendas pertencentes a CFM são apresentadas na Tabela 5.

Tabela 5: Número de observações (N), número de grupos contemporâneos para cada característica (GC), média das características (M), desvio padrão (DP), coeficiente de variação (C.V.), mínimo (MIN) e máximo (MAX) das características.

\begin{tabular}{cccccccc}
\hline Característica & $\mathrm{N}$ & $\mathrm{GC}$ & $\mathrm{M}$ & $\mathrm{DP}$ & $\mathrm{C} . \mathrm{V}$. & $\mathrm{MIN}$ & MAX \\
\hline AOL $\left(\mathrm{cm}^{2}\right)$ & 1.696 & 15 & 42,57 & 5,9046 & 13,87 & 25,48 & 65,70 \\
EGS $(\mathrm{mm})$ & 1.696 & 2 & 2,41 & 0,8473 & 32,21 & 0,60 & 5,10 \\
PESDES $(\mathrm{kg})$ & 26.904 & 1693 & 188,39 & 27,3849 & 14,54 & 80,00 & 316,00 \\
PESSOB (kg) & 17.650 & 1148 & 306,72 & 44,9869 & 14,67 & 100,00 & 490,00 \\
GP345 $(\mathrm{kg})$ & 17.526 & 1010 & 114,61 & 34,4263 & 30,04 & $-62,70$ & 473,70 \\
PE $(\mathrm{cm})$ & 9.138 & 545 & 27,66 & 3,3571 & 12,12 & 12,00 & 39,00 \\
ALT $(\mathrm{cm})$ & 14.114 & 607 & 137,16 & 5,1785 & 3,78 & 118 & 160 \\
CONF & 17.265 & 954 & 6,14 & 0,9724 & 7,65 & 2 & 9 \\
PREC & 17.237 & 954 & 6,14 & 1,0403 & 19,93 & 2 & 9 \\
MUSC & 17.264 & 954 & 5,99 & 1,0495 & 7,65 & 2 & 9 \\
\hline
\end{tabular}

AOL - área de olho de lombo; EGS - espessura de gordura subcutânea; PESDES peso a desmama; PESSOB - Pesos ao sobreano; GP345 - ganho de peso da desmama ao sobreano; PE - circunferência escrotal; ALT - altura; CONF - escore de conformação; PREC - escore de precocidade; MUSC - escore de musculosidade.

\subsubsection{FAZENDA MUNDO NOVO (REBANHO 2)}

Os dados coletados foram adicionados à base de dados da fazenda, nos computadores do Grupo de Melhoramento Animal da Faculdade de Zootecnia e Engenharia de Alimentos formando assim um banco de dados com 10.104 animais na base de dados e 14.206 animais no pedigree, neste banco de dados foram incluídos meio-irmãos e irmãos completos dos animais. As médias das características analisadas são apresentadas na Tabela 6. 
Tabela 6: Número de observações $(\mathrm{N})$, número de grupos contemporâneos para cada característica (GC), média das características (M), desvio padrão (DP), coeficiente de variação (C.V.), mínimo (MIN) e máximo (MAX) das características.

\begin{tabular}{crrrrrrr}
\hline Característica & \multicolumn{1}{c}{ N } & \multicolumn{1}{c}{ GC } & \multicolumn{1}{c}{ M } & \multicolumn{1}{c}{ DP } & \multicolumn{1}{c}{ C.V } & \multicolumn{1}{c}{ MIN } & \multicolumn{1}{c}{ MAX } \\
\hline AOL $\left(\mathrm{cm}^{2}\right)$ & 951 & 20 & 49,23 & 9,9217 & 20,15 & 25,70 & 85,70 \\
EGS $(\mathrm{mm})$ & 951 & 65 & 2,10 & 0,5715 & 27,24 & 0,60 & 4,00 \\
PESDES (kg) & 7.833 & 409 & 176,73 & 32,2903 & 18,31 & 50,00 & 324,80 \\
PESSOB (kg) & 5.623 & 276 & 305,73 & 55,3746 & 18,11 & 143,00 & 558,00 \\
GP345 (kg) & 4.876 & 579 & 135,53 & 43,4718 & 32,08 & $-47,30$ & 412,00 \\
PE $(\mathrm{cm})$ & 2.046 & 276 & 25,29 & 3,4753 & 31,74 & 15,00 & 38,00 \\
\hline
\end{tabular}

Inicialmente foram realizadas análises uni-características e posteriormente análises bi-características com estimação das correções genéticas.

\subsection{Modelos}

O modelo genérico utilizado nas análises uni-características foi:

$$
Y=X \beta+Z \mu+e \text {, em que: }
$$

Y = Vetor das variáveis dependentes (observações)

$\mathrm{X}=$ matriz de incidência associando elementos de $\beta$ a Y

$\beta=$ Vetor dos efeitos fixos

$\mathrm{Z}=$ matriz de incidência associando elementos de $\mu a \mathrm{Y}$

$\mu=$ Vetor de efeitos aleatórios de valor genético

O modelo genérico para as análises bi-características foi:

$$
\left[\begin{array}{l}
y_{1} \\
y_{2}
\end{array}\right]=\left[\begin{array}{cc}
X_{1} & 0 \\
0 & X_{2}
\end{array}\right]\left[\begin{array}{l}
\beta_{1} \\
\beta_{2}
\end{array}\right]+\left[\begin{array}{cc}
Z_{1} & 0 \\
0 & Z_{2}
\end{array}\right]\left[\begin{array}{l}
\mu_{1} \\
\mu_{2}
\end{array}\right]+\left[\begin{array}{l}
e_{1} \\
e_{2}
\end{array}\right]
$$


em que,

$\mathrm{y}_{1}=$ vetor dos registros de medidas da característica 1

$\mathrm{y}_{2}=$ vetor dos registros de medidas da característica 2

$\beta_{1}=$ vetor de efeitos fixos para a característica 1

$\beta_{2}=$ vetor de feitos fixos para característica 2

$\mu_{1}=$ vetor de efeitos aleatórios de valor genético para a característica 1

$\mu_{2}=$ vetor de efeitos aleatórios de valor genético para a característica 2

$\mathrm{X}_{1}\left(\mathrm{X}_{2}\right)=$ matriz de incidência associando elementos de $\mathrm{b}_{1}\left(\mathrm{~b}_{2}\right)$ a $\mathrm{y}_{1}\left(\mathrm{y}_{2}\right)$

$\mathrm{Z}_{1}\left(\mathrm{Z}_{2}\right)=$ matriz de incidência associando elementos de $\mu_{1}\left(\mu_{2}\right)$ a $\mathrm{y}_{1}\left(\mathrm{y}_{2}\right)$

\subsubsection{EFEITOS FIXOS (VETOR $\beta$ )}

De acordo com a característica analisada, foram considerados os seguintes efeitos fixos (Vetor $\beta$ ):

\section{Peso a desmama:}

Para as fazendas CFM foi utilizado o grupo contemporâneo a desmama (que inclui fazenda + ano + sexo + estação de nascimento + grupo de manejo a desmama), a idade do animal na medição como covariável linear e a idade da mãe ao parto como covariável linear e quadrática. Para a fazenda Mundo Novo foi utilizado o grupo contemporâneo à desmama (que inclui ano + sexo + grupo de manejo a desmama), a idade do animal na medida como covariável linear e a idade da mãe ao parto como covariável linear e quadrática. 


\section{Peso ao Sobreano:}

Para as fazendas CFM foi utilizado o grupo de contemporâneos ao sobreano (que inclui grupo de contemporâneos a desmama + grupo de manejo ao sobreano) e a idade do animal na medida como covariável linear.

Para a fazenda Mundo Novo foi utilizado o grupo de contemporâneos ao sobreano (que inclui grupo de contemporâneos a desmama + grupo de manejo ao sobreano) e a idade do animal na medida como covariável linear.

\section{Ganho de Peso da Desmama ao Sobreano:}

Para as fazendas CFM foi utilizado o grupo de contemporâneos ao sobreano (que inclui grupo de contemporâneos a desmama + grupo de manejo ao sobreano).

Para a fazenda Mundo Novo foi utilizado o grupo de contemporâneos ao sobreano (que inclui grupo de contemporâneos a desmama + grupo de manejo ao sobreano).

\section{Perímetro Escrotal:}

Para as fazendas CFM foi utilizado o grupo de contemporâneos ao sobreano (que inclui grupo de contemporâneos a desmama + grupo de manejo ao sobreano) e a idade do animal a medição como covariável linear.

Para a fazenda Mundo Novo foi utilizado o grupo de contemporâneos ao sobreano (que inclui grupo de contemporâneos a desmama + grupo de manejo ao sobreano) e a idade do animal na medida como covariável linear.

\section{5. Área de Olho de Lobo:}

Para as fazendas CFM foi utilizado o grupo de contemporâneos de AOL (que inclui fazenda + grupo de manejo ao sobreano) e a idade do animal a medição como covariável linear.

Para a fazenda Mundo Novo foi utilizado o grupo de contemporâneos de AOL (que inclui safra do animal + sexo) e a idade do animal na medida como covariável linear. 


\section{Espessura de Gordura Subcutânea:}

Para as fazendas CFM foi utilizado o grupo de contemporâneos de AOL (que inclui fazenda) e a idade do animal a medida como covariável linear.

Para a fazenda Mundo Novo foi utilizado o grupo de contemporâneos de AOL (que inclui safra do animal + sexo) e a idade do animal a medição como covariável linear.

As características a seguir só foram analisadas para as fazendas CFM.

\section{Altura:}

Para as fazendas CFM foi utilizado o grupo de contemporâneos ao sobreano (que inclui grupo de contemporâneos a desmama + grupo de manejo ao sobreano) e a idade do animal a medição como covariável linear.

\section{Conformação:}

Para as fazendas CFM foi utilizado o grupo de contemporâneos ao sobreano (que inclui grupo de contemporâneos a desmama + grupo de manejo ao sobreano) e a idade do animal a medição como covariável linear.

\section{Precocidade:}

Para as fazendas CFM foi utilizado o grupo de contemporâneos ao sobreano (que inclui grupo de contemporâneos a desmama + grupo de manejo ao sobreano) e a idade do animal a medição como covariável linear.

\section{Musculosidade:}

Para as fazendas CFM foi utilizado o grupo de contemporâneos ao sobreano (que inclui grupo de contemporâneos a desmama + grupo de manejo ao sobreano) e a idade do animal a medição como covariável linear.

O procedimento PROC GLM (SAS 6.12) foi utilizado para estimação dos efeitos fixos e verificação de sua significância. Os grupos contemporâneos foram formados com a inclusão dos efeitos fixos significativos. 


\subsubsection{EFEITOS GENÉticos (VETOR $\mu)$}

1. Para as características área de olho de lombo (AOL), espessura de gordura subcutânea (EGS), peso ao sobreano (PESSOB), Perímetro escrotal (PE), altura (ALT), conformação (C), precocidade (P) musculosidade (M) e ganho de peso da desmama ao sobreano (GP345) foi incluído apenas efeito genético aditivo direto. E para peso a desmama foram incluídos efeito genético aditivo direto, efeito genético aditivo materno e efeito de ambiente permanente da vaca.

\subsection{Metodologia de ANÁLISE GenÉticA}

Os componentes foram estimados por máxima verossimilhança restrita utilizando-se o software MTDFREML - Multiple Trait Derivative Free Restricted Maximum Likelihood (BOLDMAN et al., 1993) que usa técnicas de matrizes esparsas através da incorporação do SPARSPACK (GEORGE et al., 1980) e fatoração de Choleski para obter o log do determinante da matriz dos coeficientes e a soma de quadrados generalizada dos resíduos. Os componentes de variância e covariância são estimados por máxima verossimilhança restrita, usando um algoritmo não derivativo (SMITH \& GRASER, 1986).

A otimização da função de verossimilhança é obtida por um algoritmo conhecido como “downhill simplex” ou ameba (NELDER \& MEAD, 1965).

Em cada ciclo de iteração, a variância dos valores do logaritmo da função de verossimilhança no simplex é calculada. O critério de convergência é atingido quando essa variância é igual ou menor que $10^{-9}$. Como há possibilidade de se obter máximos locais ao invés do máximo global (PRES et al., 1986), várias reinicializações foram executadas no sentido de se assegurar a convergência no máximo global da função de verossimilhança. 


\subsection{SELEÇÃo INDIRETA}

Para as simulações de ganho genético através da seleção indireta utilizou-se o seguinte cenário:

- $10 \%$ dos melhores touros (intensidade de seleção de 1,76)

- $80 \%$ das melhores vacas (intensidade de seleção de 0,35 )

Aplicando-se na fórmula:

$$
\begin{gathered}
\qquad \Delta G_{y}=i r_{g} \sqrt{h_{x}^{2} h_{y}^{2}} \sigma_{p_{y}} \\
i \quad=\text { intensidade de seleção aplicada na característica } \mathbf{X} \\
r_{g} \quad=\text { correlação genética entre as características } \mathbf{X} \text { e } \mathbf{Y} \\
h_{x}^{2} \quad=\text { herdabilidade da característica } \mathbf{X} \\
h_{y}^{2} \quad=\text { herdabilidade da característica } \mathbf{Y} \\
\sigma_{p_{y}}=\text { desvio padrão fenotípico da característica } \mathbf{Y}
\end{gathered}
$$




\section{RESUltados E DiscuSsão}

\subsection{HERDABILIDADE}

\subsubsection{MEDIDAS FEITAS POR ULTRA-SONOGRAFIA}

\subsubsection{1.ÁREA DE OLHO DE LOMBO (AOL)}

As estimativas do coeficiente de herdabilidade são apresentadas na Figura 10. A análise desta figura mostra que a estimativa obtida para o rebanho 1 foi inferior à encontrada no rebanho 2. Esta diferença de magnitude pode ser explicada pelo fato de o rebanho 1 apresentar medidas em uma só safra, além da participação, no conjunto de dados, de 390 animais com pai desconhecido (23\% da população analisada). Verificou-se ainda que 64\% das mães são filhas de pais desconhecidos (em sua maioria reprodutores múltiplos). Isto poderia alterar a estimação dos componentes de variância.

A estimativas de coeficientes de herdabilidade encontradas foram 0,19 no rebanho 1 e 0,41 no rebanho 2. Reverter et al. (2000) obtiveram estimativa igual a 0,37 para machos da raça Angus e 0,41 para machos da raça Hereford portanto, semelhante ao obtido no rebanho 2. Por outro lado Shepard et al. (1996), encontraram uma estimativa de coeficiente de herdabilidade de 0,11 em animais da raça Angus e Moser et al. (1998) obtiveram uma estimativa de 0,29 $\pm 0,04$ em animais da raça Brangus.

Deve-se salientar, no entanto, que a falta de estudos semelhantes com animais da raça Nelore, bem como o padrão de idade à mensuração adotado no Brasil, dificultam as comparações com dados da literatura. 


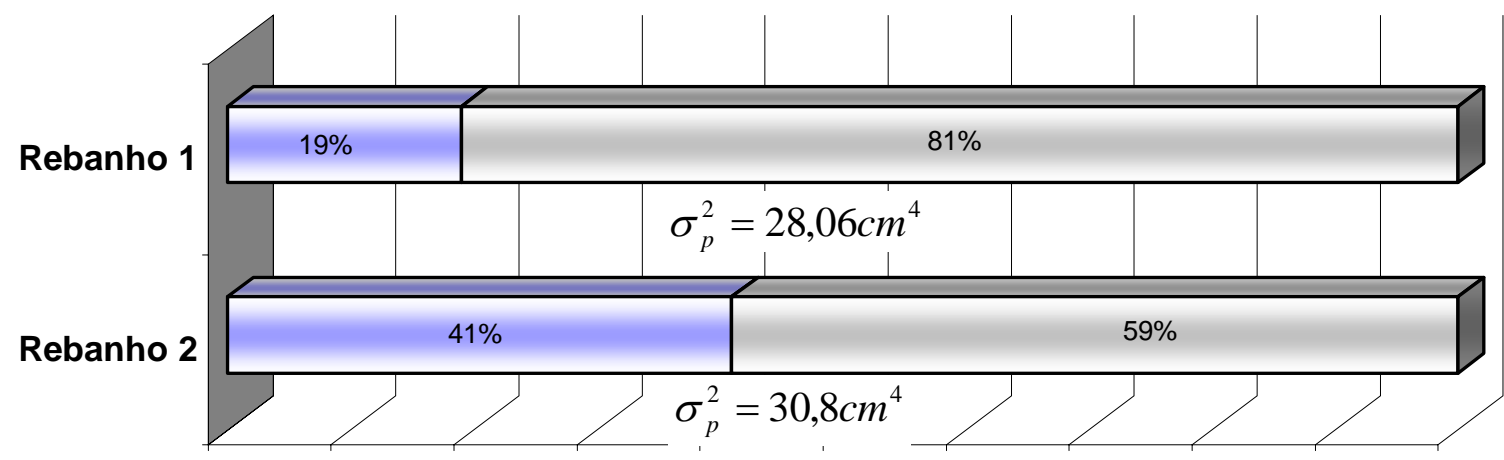

$\square$ Efeito Genético Aditivo Direto $\quad \square$ Efeitos Residuais

FIGURA 10 - Proporções da variância total devida aos efeitos genéticos aditivos direto $\left(\mathrm{h}^{2}\right)$ e efeitos residuais $\left(\mathrm{e}^{2}\right)$ para área de olho de lombo (obtidas em análises uni-característica).

A variação da herdabilidade encontrada quando esta foi estimada em análises bi-características nos rebanhos 1 e 2 (Figuras 11 e 12) pode ser devida à diferença encontrada no número de animais do banco de dados, pois este varia conforme a característica analisada em conjunto com a característica de AOL. Os melhores valores devem ser de 0,19 (rebanho 1) e 0,36 (rebanho 2), pois são os que foram estimados dos maiores conjunto de dados.

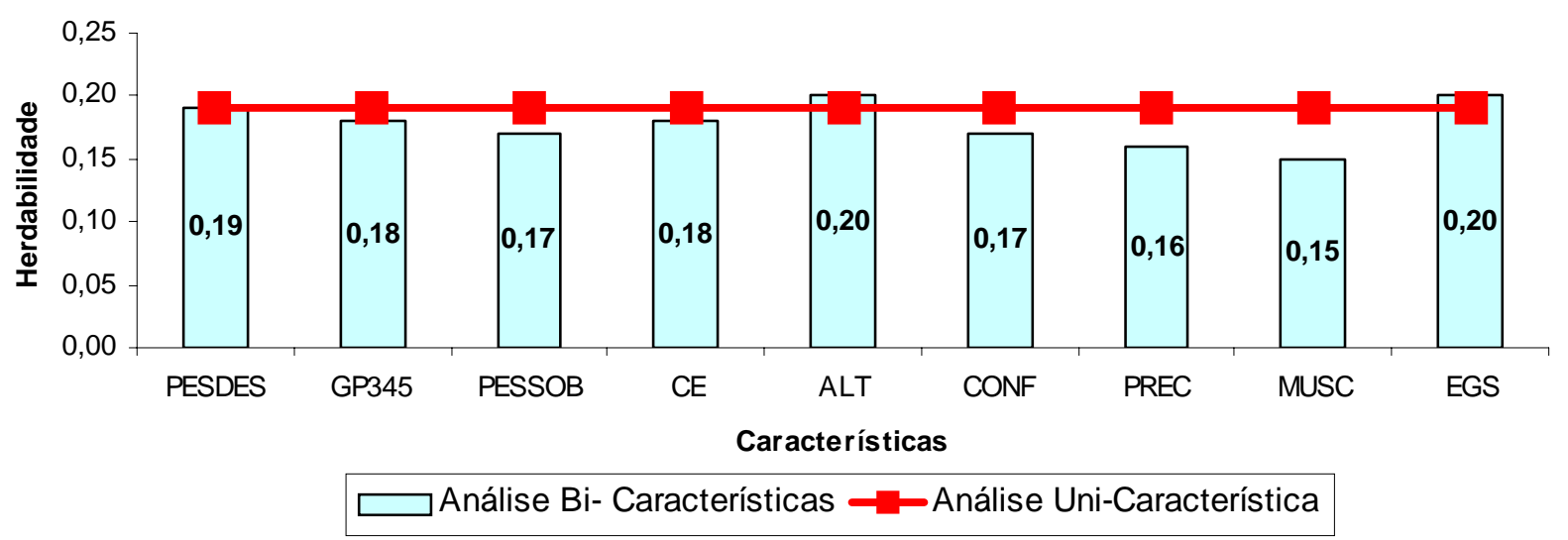

FIGURA 11 - Comparação da variação da estimativa de herdabilidade de AOL obtidas em análises uni e bi-características no rebanho 1. 




FIGURA 12 - Comparação da variação das estimativas de herdabilidade de AOL obtidas em análises uni e bi-característica no rebanho 2.

\subsubsection{ESPESSURA DE GORDURA SUBCUTÂNEA (EGS)}

As estimativas do coeficiente de herdabilidade para a característica EGS foram 0,04 para o rebanho 1 e 0,19 para o rebanho 2 (Figura 9). A magnitude dessas estimativas pode ter sido influenciada pela idade de medição, pois os animais da raça Nelore apresentam um amadurecimento fisiológico mais tardio que os Bos taurus de origem britânica. Outro fator que pode ter influenciado foi à presença de animais com pais desconhecidos (reprodutores múltiplos), já que cerca de 23\% dos garrotes mensurados e $64 \%$ de suas mães não apresentaram pais conhecidos. Verificou-se também que os animais do rebanho 1 estavam confinados por um período menor que os animais do rebanho 2 .

Observando-se a Tabela 7, pode-se inferir que o banco de dados de EGS não apresenta uma distribuição normal. No entanto, quando esses dados são apresentados graficamente agrupados em intervalos de valores, como proposto na Tabela 8, a distribuição tende à normalidade, conforme pode ser observado na Figura 14. Um outro fator que pode ter levado a estimativas de pequena monta para o coeficiente de herdabilidade para EGS é a própria imprecisão das medições em animais da raça Nelore na faixa etária em que os animais foram medidos, pois uma grande quantidade de animais apresentava valores muito pequenos de EGS, dificultando a 
diferenciação das medidas e, conseqüentemente, diminuindo a variabilidade dos animais.

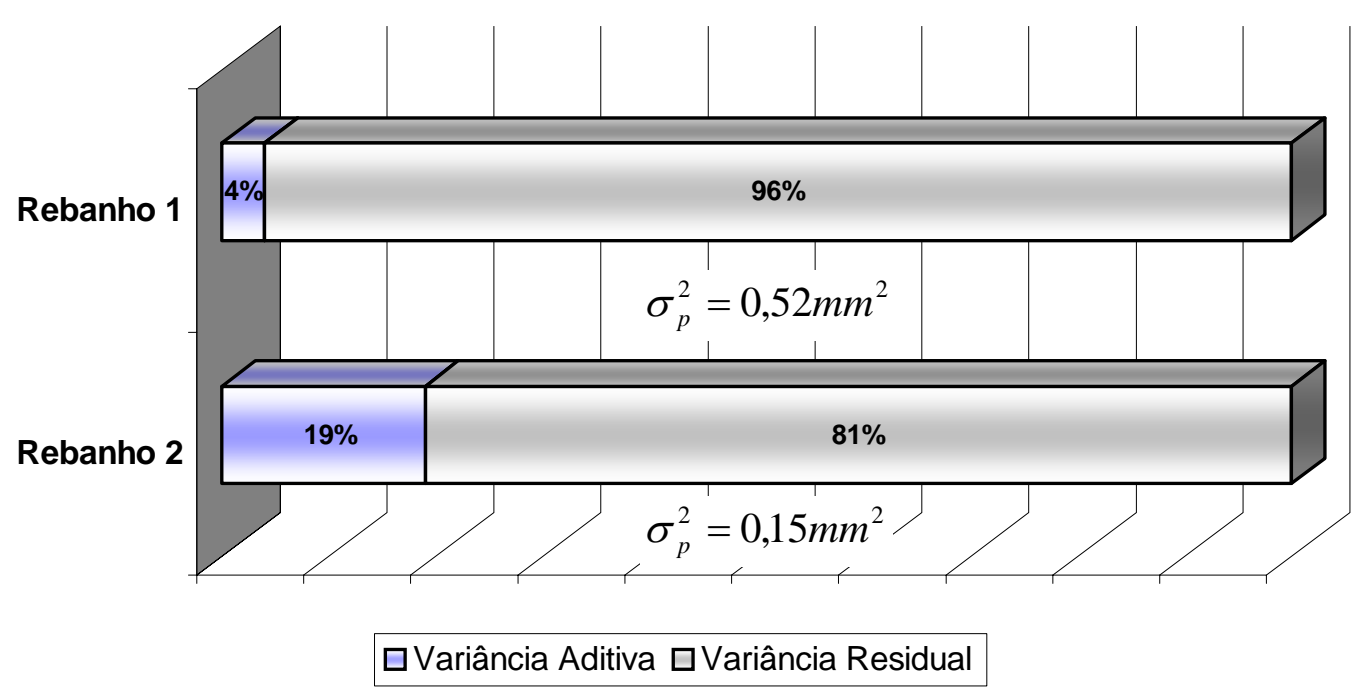

FIGURA 13 - Proporções da variância total devida aos efeitos genéticos aditivos diretos $\left(\mathrm{h}^{2}\right)$ e efeitos residuais $\left(\mathrm{e}^{2}\right)$ para espessura de gordura subcutânea (estimados em análises uni-característica).

Tabela 7: Freqüência das medidas de EGS.

\begin{tabular}{rrrrr}
\hline EGS & Freqüência & Porcentagem & Freqüência Cumulativa & Porcentagem Cumulativa \\
\hline 0,0 & 4 & 0,24 & 4 & 0,24 \\
0,6 & 14 & 0,83 & 18 & 1,06 \\
0,9 & 1 & 0,06 & 19 & 1,12 \\
1,1 & 181 & 10,67 & 200 & 11,79 \\
1,2 & 10 & 0,59 & 210 & 12,38 \\
1,7 & 319 & 18,81 & 529 & 31,19 \\
1,8 & 41 & 2,42 & 570 & 33,61 \\
1,9 & 1 & 0,06 & 571 & 33,67 \\
2,3 & 453 & 26,71 & 1024 & 60,38 \\
2,4 & 13 & 0,77 & 1037 & 61,14 \\
2,6 & 1 & 0,06 & 1038 & 61,20 \\
2,8 & 196 & 11,56 & 1234 & 72,76 \\
2,9 & 100 & 5,90 & 1334 & 78,66 \\
3,0 & 9 & 0,53 & 1343 & 79,19 \\
3,4 & 215 & 12,68 & 1558 & 91,86 \\
3,5 & 8 & 0,47 & 1566 & 92,33 \\
3,6 & 4 & 0,24 & 1570 & 92,57 \\
3,8 & 5 & 1575 & 92,87 \\
4,0 & 94 & 5,29 & 1669 & 98,41 \\
4,1 & 1 & 1670 & 98,47 \\
4,3 & 3 & 0,06 & 1673 & 98,64 \\
4,5 & 17 & 1,18 & 1690 & 99,65 \\
4,6 & 1 & 169 & 99,71 \\
5,1 & 5 & 0,06 & 1696 & 100,00 \\
\hline
\end{tabular}


Tabela 8: Classe de Medidas de EGS

\begin{tabular}{clr}
\hline Classe & \multicolumn{1}{c}{ Intervalo de Medida } & Freqüência \\
& & 4 \\
1 & Medidas menor que 0,5 mm & 15 \\
2 & Medidas de 0,5 a 1,0 mm & 191 \\
3 & Medidas de 1,0 a 1,5 mm & 361 \\
4 & Medidas de 1,5 a 2,0 mm & 466 \\
5 & Medidas de 2,0 a 2,5 mm & 297 \\
6 & Medidas de 2,5 a 3,0 mm & 224 \\
7 & Medidas de 3,0 a 3,5 mm & 17 \\
8 & Medidas de 3,5 a 4,0 mm & 98 \\
9 & Medidas de 4,0 a 4,5 mm & 6 \\
10 & Medidas acima de 4,5 mm \\
\hline
\end{tabular}

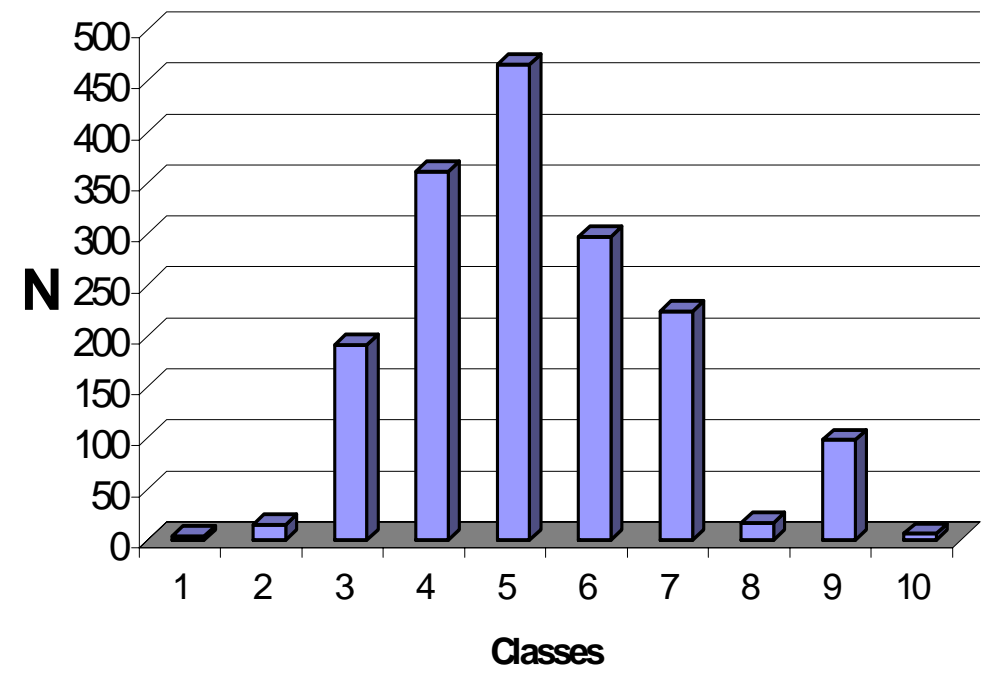

FIGURA 14 - DISTRIBUIÇÃO DE MEDIDAS DE EGS DO REBANHO 1 DISTRIBUÍDO EM CLASSES DE MEDIDAS

No rebanho 1 foram realizadas medições em apenas uma safra de animais enquanto que o rebanho 2 apresenta quatro safras de animais medidos. Isto pode ter se refletido nas estimativas de herdabilidade encontradas.

Quando comparado com valores encontrados por Reverter et al. (2000) para machos da raça Hereford $(0,09)$ verificou-se que a herdabilidade encontrada para o rebanho 1 não apresenta muita disparidade, pois como citado anteriormente o Nelore apresenta um amadurecimento fisiológico tardio, e conseqüentemente uma deposição 
de gordura mais tardia. E quando comparado com o valor encontrado $(0,04)$ por Turner et al. (1990) para animais da raça Hereford, os valores são iguais. Ao comparar com as estimativas obtidas pelos autores citados para garrotes da raça Angus $(0,47)$, verifica-se que os valores encontrados neste experimento são mais baixos. Em animais Brangus, Moser et al. (1998) encontraram uma herdabilidade de 0,11 e em animais Angus medidos ao sobreano, Shepard et al. (1996) encontraram uma herdabilidade de 0,56 para EGS, o que demonstra que há uma grande variabilidade para a característica de EGS.

A variação da herdabilidade quando esta foi estimada em análises bicaracterísticas (Figuras 15 e 16) pode ter sido causada pela diferença no número de animais do banco de dados, pois se verificou que há uma variação pequena entre as análises bi-caracteríticas e de algumas análises bi-características em relação a herdabilidade estimada em análise uni-caracterítica.

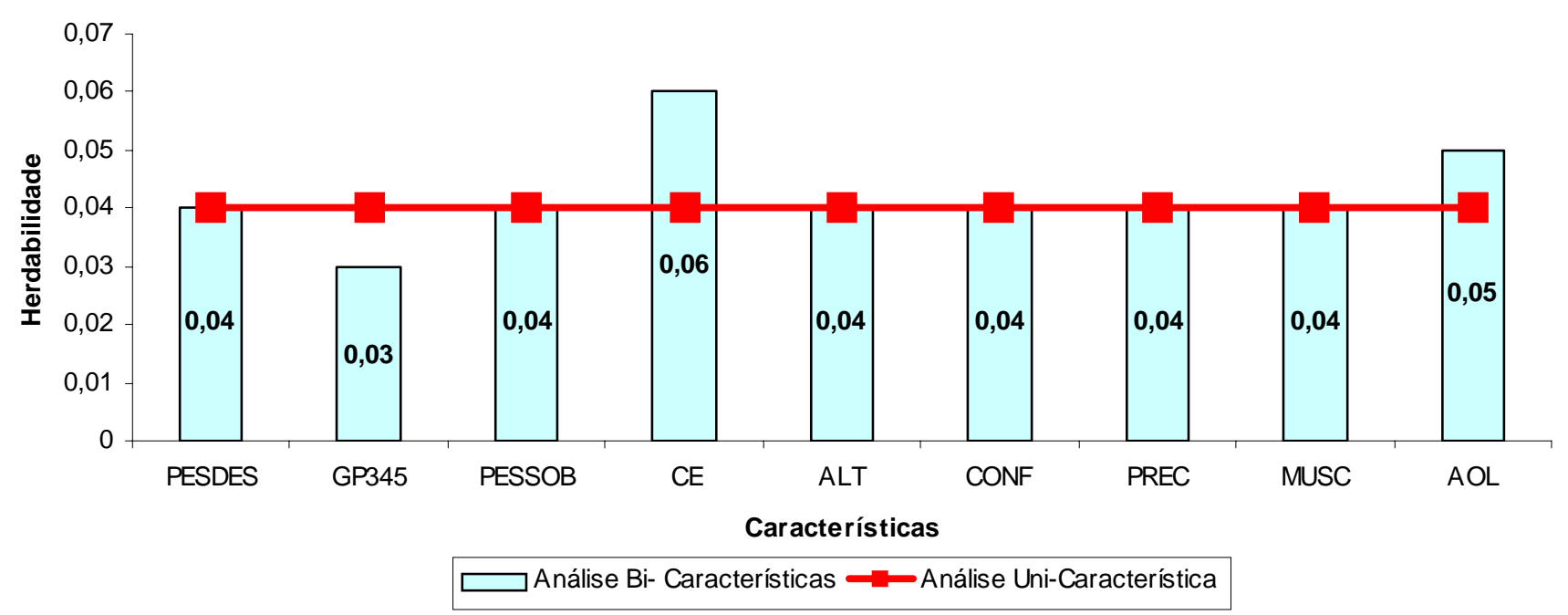

FIGURA 15 - Comparação da variação da estimativa de herdabilidade de EGS realizada em análise uni e bi-características no rebanho 1. 


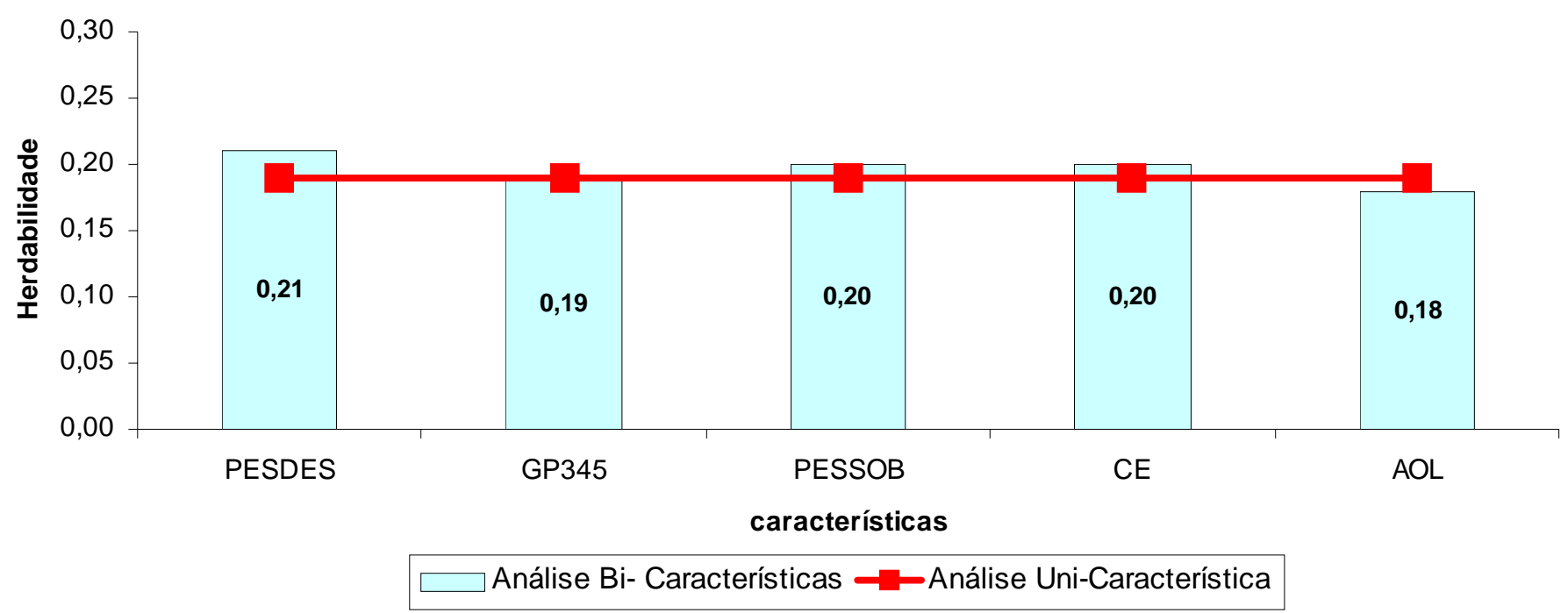

FIGURA 16 - Comparação da variação da estimativa de herdabilidade de EGS obtida em análise uni e bi-características no rebanho 2.

\subsubsection{MedidAs de Desenvolvimento Ponderal}

\subsubsection{Peso a Desmama (PESDES)}

Os coeficientes de herdabilidade obtidos para peso a desmama é apresentada na Figura 17 para os rebanhos 1 e 2.

Os valores encontrados são superiores aos encontrados por Eler et al. (1995), e inferiores ao de Eler et al. (1996). A média relatada por Lôbo et al. (2000) é de 0,29 .

Pereira (2000) encontrou uma variação de 0,11 a 0,29 para herdabilidade direta, 0,04 a 0,06 para herdabilidade materna e de 0,09 a 013 para ambiente permanente da vaca dado como proporção da variância fenotípica $\left(\mathrm{c}^{2}\right)$. Dependendo do banco de dados que foi analisado. Em relação ao efeito materno, o rebanho 2 apresenta uma herdabilidade maior do que o rebanho 1. 


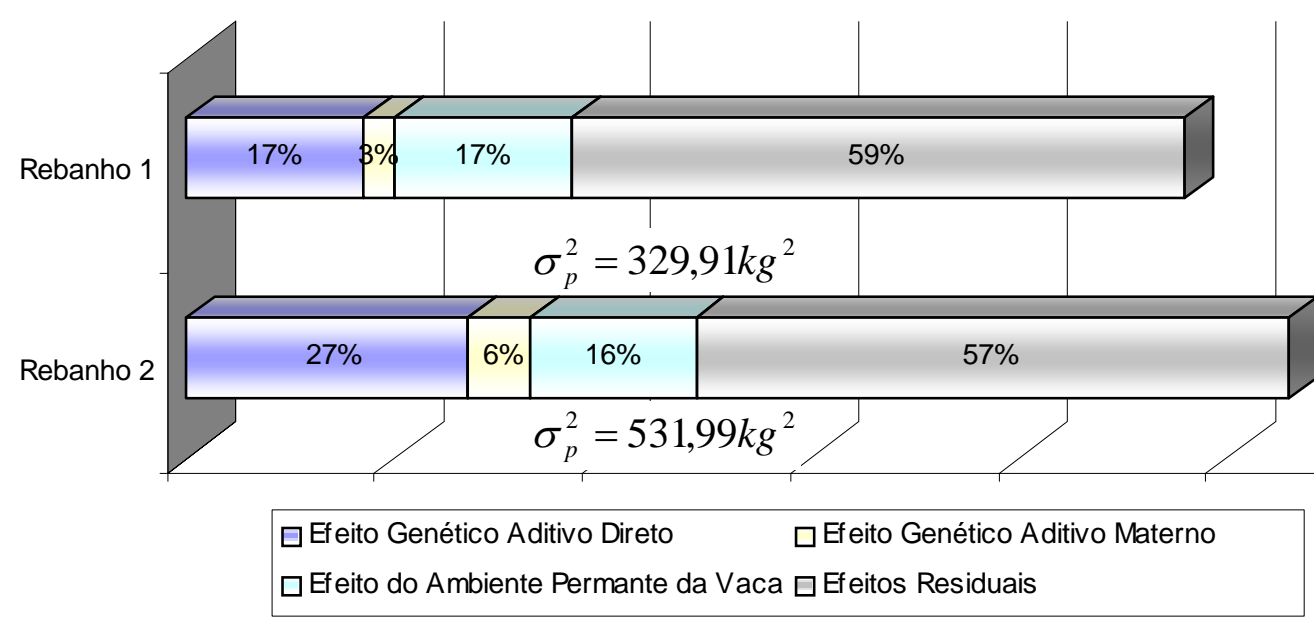

FIGURA 17 - Proporções da variância total devida aos efeitos genéticos aditivos diretos $\left(h_{a}^{2}\right)$, materno $\left(h_{m}^{2}\right)$, ambiente permanente da vaca $\left(\mathrm{c}^{2}\right)$ e efeitos residuais $\left(\mathrm{e}^{2}\right)$ para peso a desmama (estimados em análises uni-característica).

\subsubsection{GANHo de Peso da Desmama ao Sobreano (GP345)}

Os valores de herdabilidade estimados para GP345 são 0,30 e 0,21 (Figura 18) respectivamente para os rebanhos 1 e 2. Os valores são de magnitude similar aos encontrados por Pereira (2000) que obteve valores entre 0,23 e 0,26, e Pereira et al. (1999) com valor igual a 0,26. O valor de herdabilidade para o rebanho 1 é similar a média $(0,33)$ publicada por Lôbo et al. (2000). 




FIGURA 18 - Proporções da variância total devida aos efeitos genéticos aditivos diretos $\left(\mathrm{h}^{2}\right)$ e efeitos residuais $\left(\mathrm{e}^{2}\right)$ para ganho de peso da desmama ao sobreano (estimados em análises uni-característica).

\subsubsection{PESO AO SOBREANO (PESSOB)}

Os coeficientes de herdabilidade estimados para os rebanhos 1 e 2 (0,32 e 0,29 respectivamente) encontram-se dentro da amplitude dos valores obtidos para a raça Nelore de 0,30 por Eler et al. (1996) e 0,64 por Biffani et al. 1999. Pereira (2000) obteve herdabilidade igual 0,32 (Figura 19). 


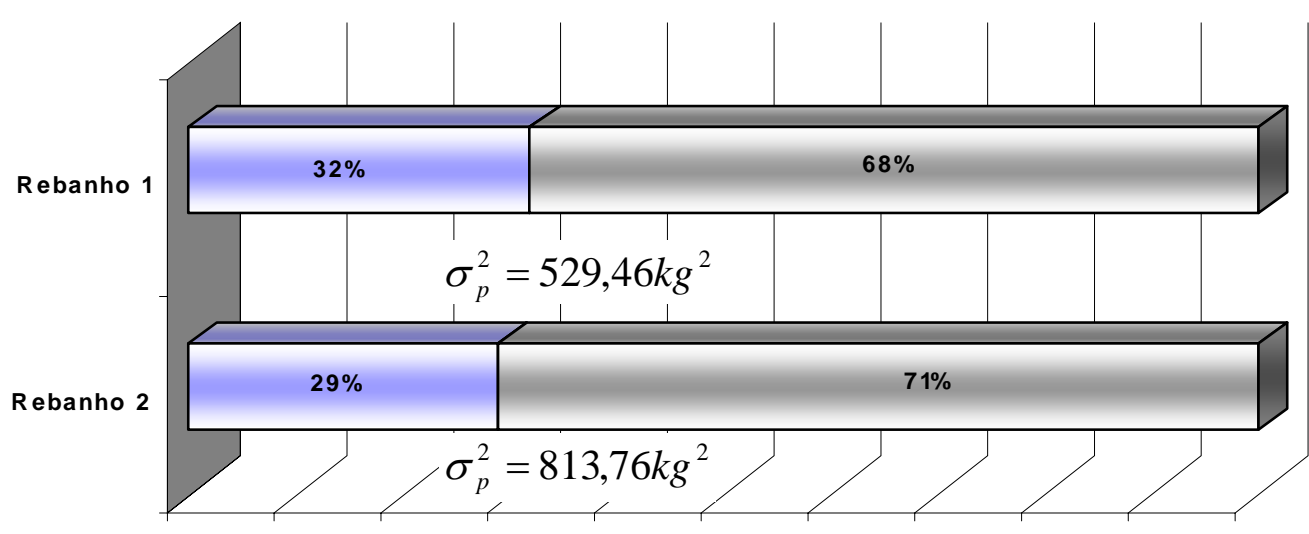

$\boxminus$ Efeito Genético Aditivo Direto $\boxminus$ Efeitos Residuais

FIGURA 19 - Proporções da variância total devida aos efeitos genéticos aditivos diretos $\left(h^{2}\right)$ e efeitos residuais $\left(\mathrm{e}^{2}\right)$ peso ao sobreano (estimados em análises uni-característica).

\subsubsection{Perímetro Escrotal (PE)}

As herdabilidades encontradas para perímetro escrotal são 0,53 e 0,34 respectivamente para os rebanho 1 e 2 (Figura 20). São valores que se encontram dentro da faixa encontrada na literatura para bovinos da raça Nelore que vai de 0,31 (Gressler et al., 1998) até 0,77 (Quirino \& Bergmann, 1998).

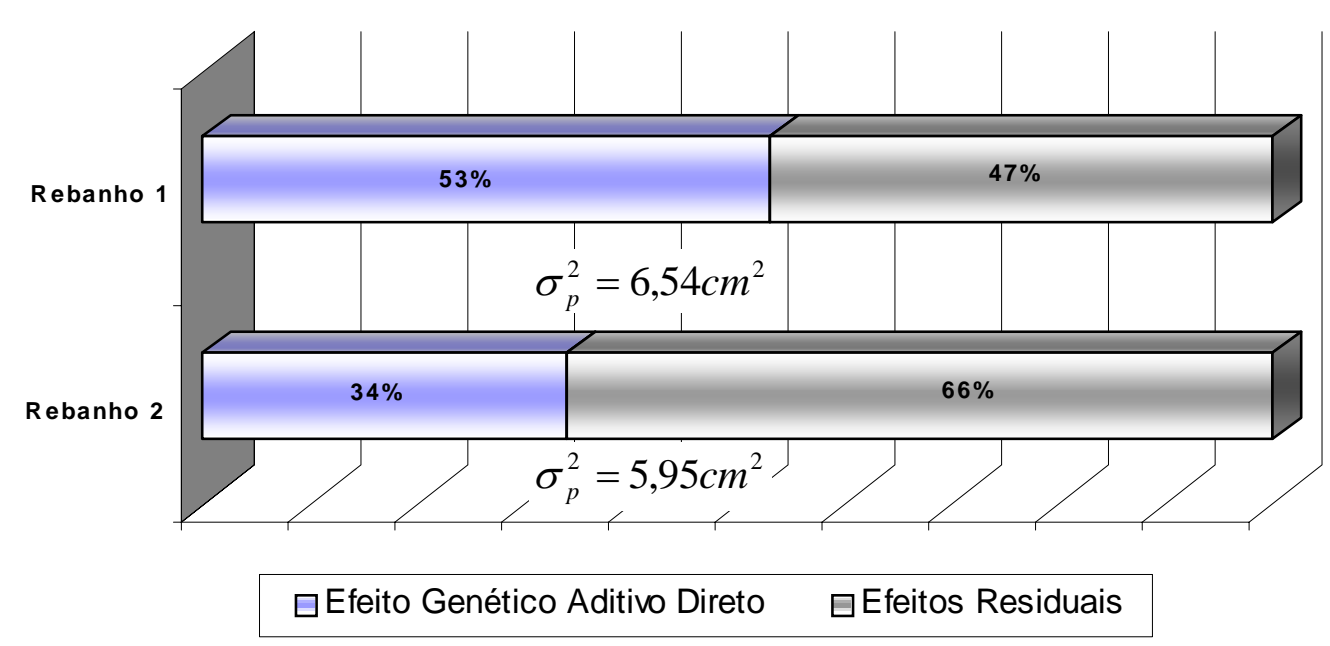

FIGURA 20 - Proporções da variância total devida aos efeitos genéticos aditivos diretos $\left(\mathrm{h}^{2}\right)$ e efeitos residuais $\left(\mathrm{e}^{2}\right)$ para perímetro escrotal (estimados em análises uni-característica). 


\subsubsection{ALTURA (ALT)}

A herdabilidade para altura foi estimada somente para o rebanho 1 encontrando-se um valor de 0,20 (Figura 21). Este valor é inferior ao encontrado $(0,50)$ para animais Angus (http://www.angus.org/sireeval/genintro.html) e ao valor $(0,27)$ relatado Ferraz e Eler (2000). Possivelmente esta diferença entre as herdabilidades deve-se a amostra utilizada.

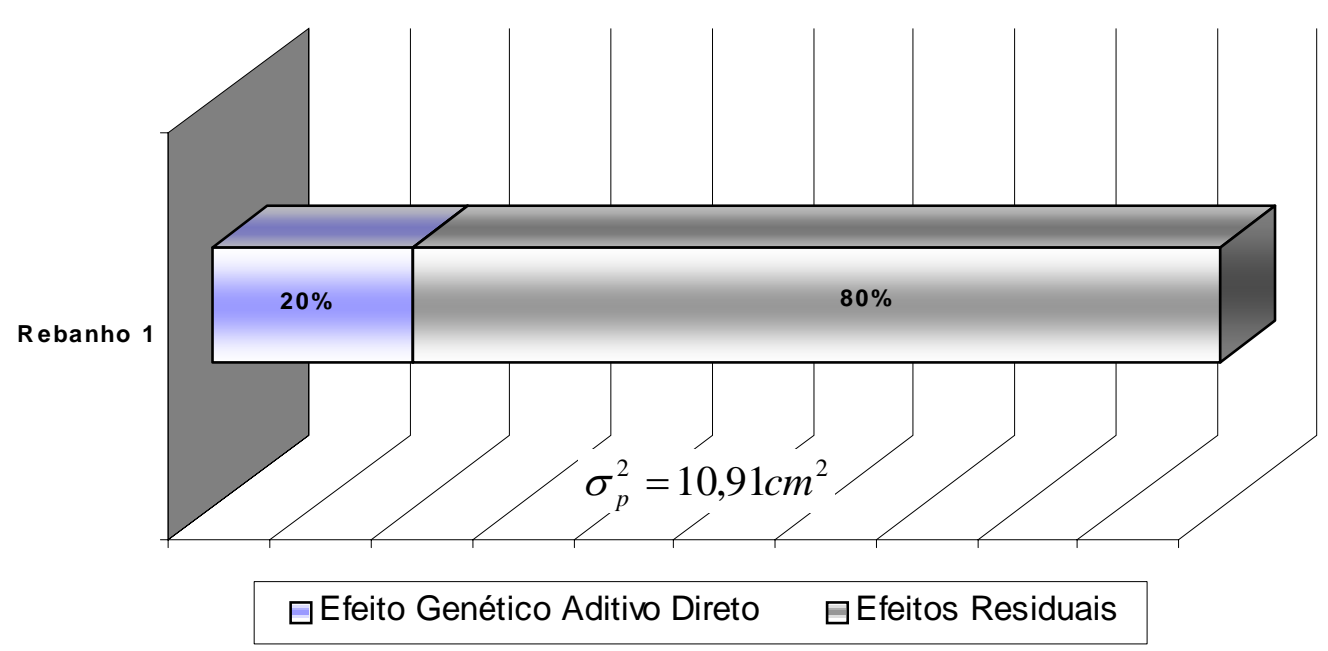

FIGURA 21 - Proporções da variância total devida aos efeitos genéticos aditivos diretos $\left(\mathrm{h}^{2}\right)$ e efeitos residuais $\left(\mathrm{e}^{2}\right)$ para altura (estimados em análises uni-característica).

\subsubsection{ESCORES VISUAIS}

\subsubsection{MUSCULOSIDADE (MUSC)}

O valor de herdabilidade encontrado para MUSC foi de 0,18 (Figura 22). Este valor é inferior ao encontrado por Ferraz e Eller (2000) (0,25) e Koury Filho (2001), encontrou valor de mesma magnitude $(0,17)$. 


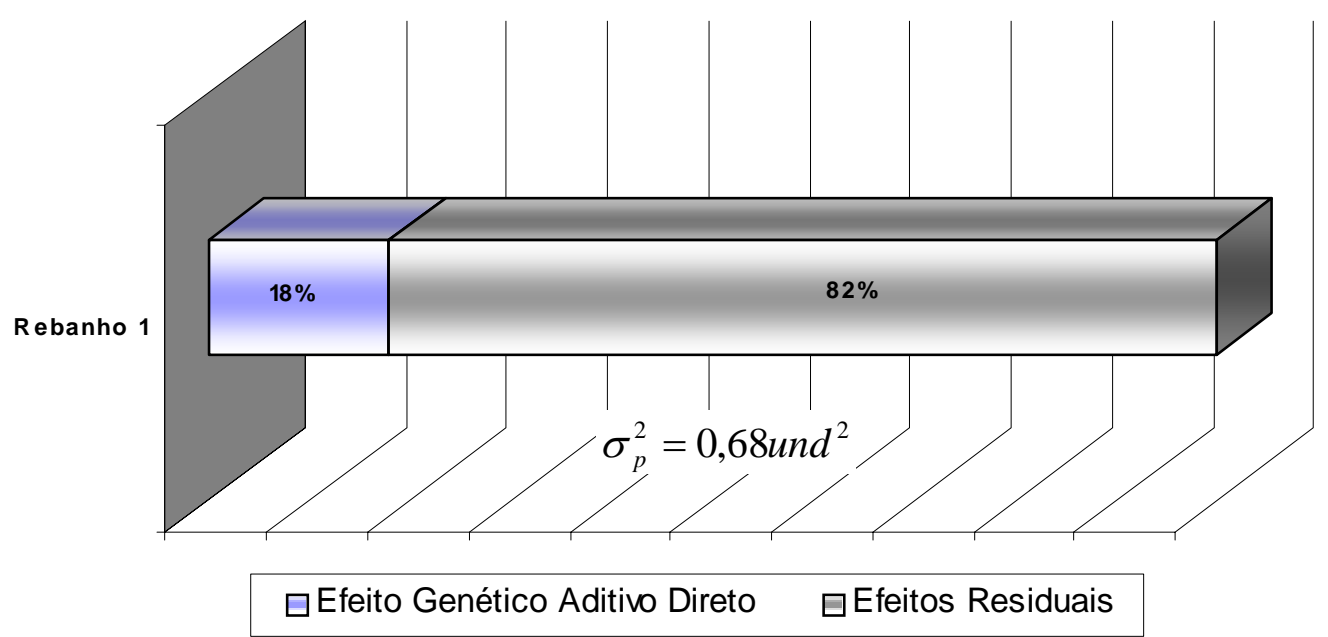

FIGURA 22 - Proporções da variância total devida aos efeitos genéticos aditivos diretos $\left(\mathrm{h}^{2}\right)$ e efeitos residuais $\left(\mathrm{e}^{2}\right)$ para musculosidade (estimados em análises uni-característica).

\subsubsection{CONFORMAÇÃo (CONF)}

O valor estimado para CONF $(0,13)$ (Figura 23) é inferior aos encontrados por Ferraz e Eler $(2000)(0,23)$ e aproximadamente igual do encontrado por Koury Filho $(2001)(0,12)$

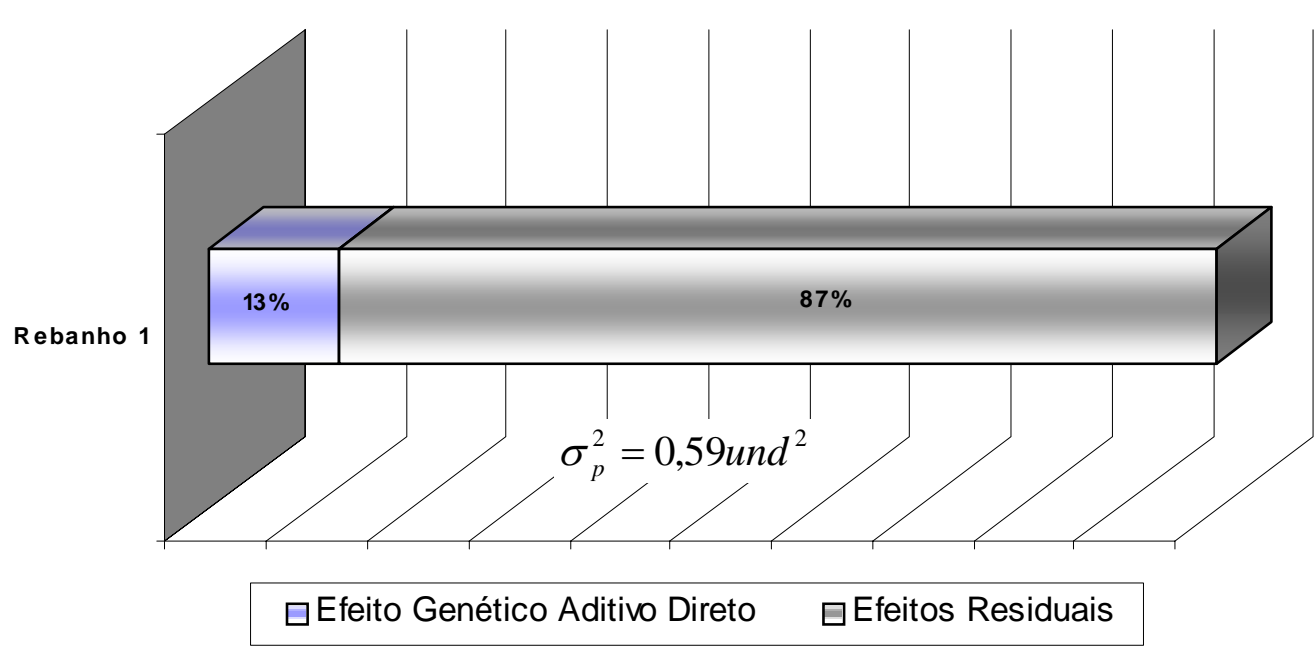

FIGURA 23 - Proporções da variância total devida aos efeitos genéticos aditivos diretos $\left(\mathrm{h}^{2}\right)$ e efeitos residuais $\left(\mathrm{e}^{2}\right)$ para conformação (estimados em análises uni-característica). 


\subsubsection{PRECOCIDADE (PREC)}

A herdabilidade estimada para PREC foi de 0,17 (Figura 24) que se encontra no intervalo para raça Nelore de 0,10 (Koury Filho, 2000) e 0,24 (Ferraz e Eler, 2000).

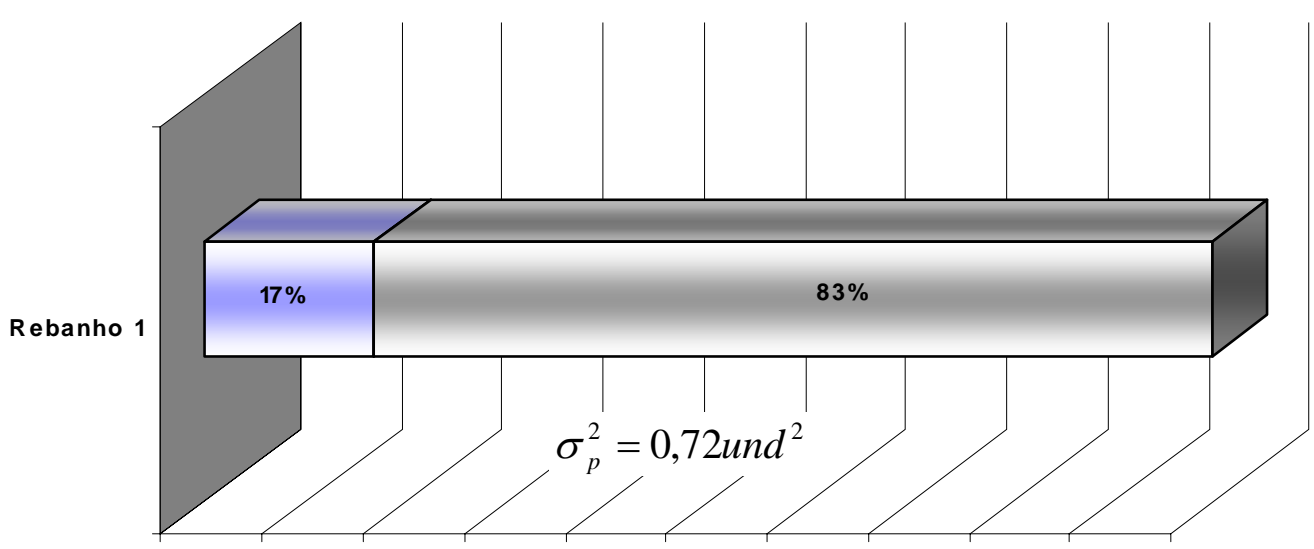

$\boxminus$ Efeito Genético Aditivo Direto $\boxminus E$ feitos Residuais

FIGURA 24 - Proporções da variância total devida aos efeitos genéticos aditivos diretos $\left(\mathrm{h}^{2}\right)$ e efeitos residuais $\left(\mathrm{e}^{2}\right)$ para precocidade (estimados em análises uni-característica). 


\subsection{CORRELAÇõES GENÉTICAS}

As correlações encontradas entre as características de carcaça mensuradas por ultra-sonografia (AOL e EGS) e as demais características de desenvolvimento ponderal e escores visuais (somente rebanho 1) são apresentadas nas Figuras 21 a 27.

\subsubsection{CORRELAÇões GENÉTICAS DE AOL COM CARACTERÍSTICA DE DESENVOLVIMENTO PONDERAL}

Correlação da área de olho de lombo com as características de desenvolvimento ponderal em ambos os rebanhos são apresentadas nas Figuras 25 e 26.

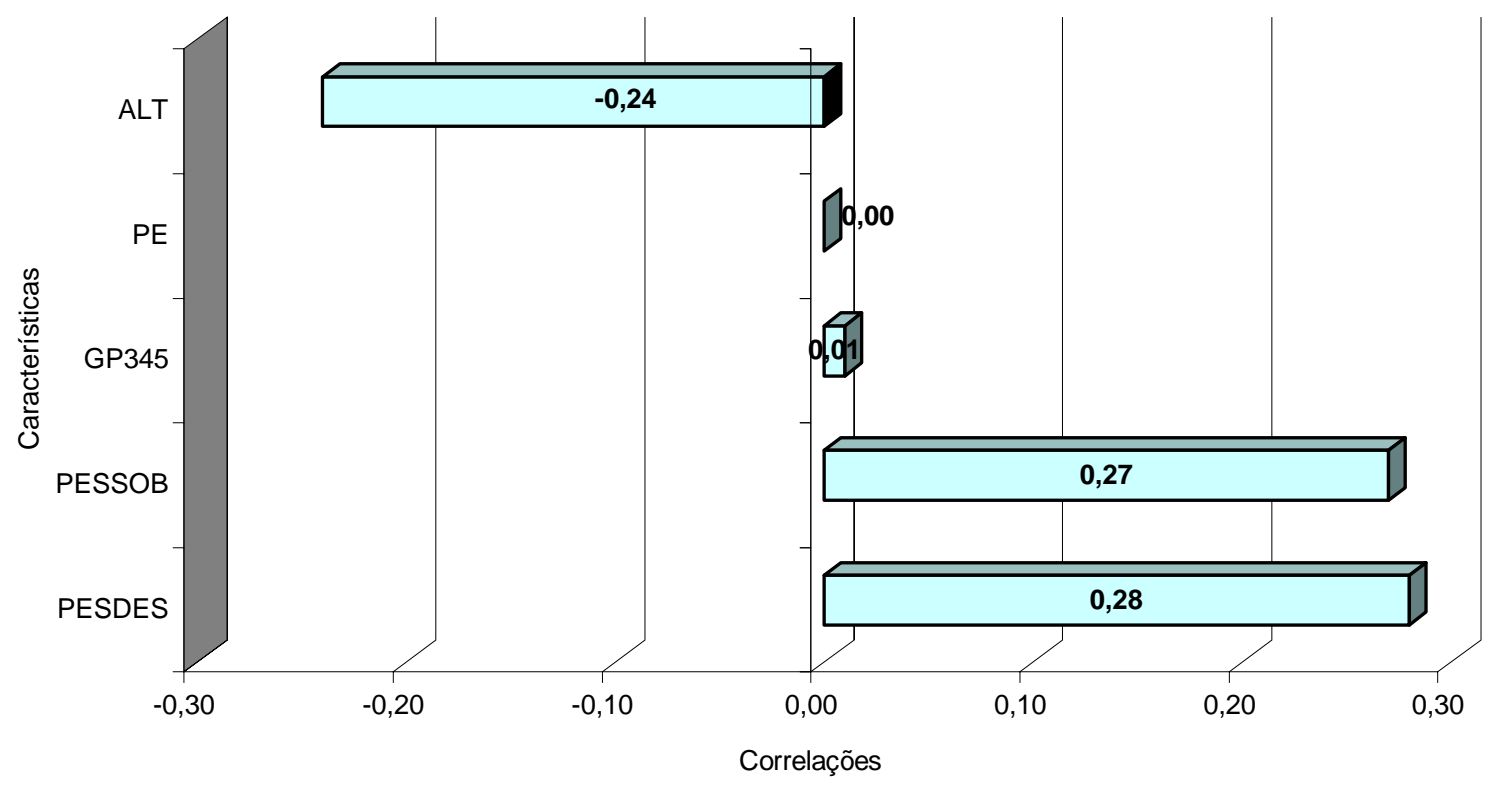

FIGURA 25 - Correlações genéticas entre AOL e características de desenvolvimento ponderal para o rebanho 1 


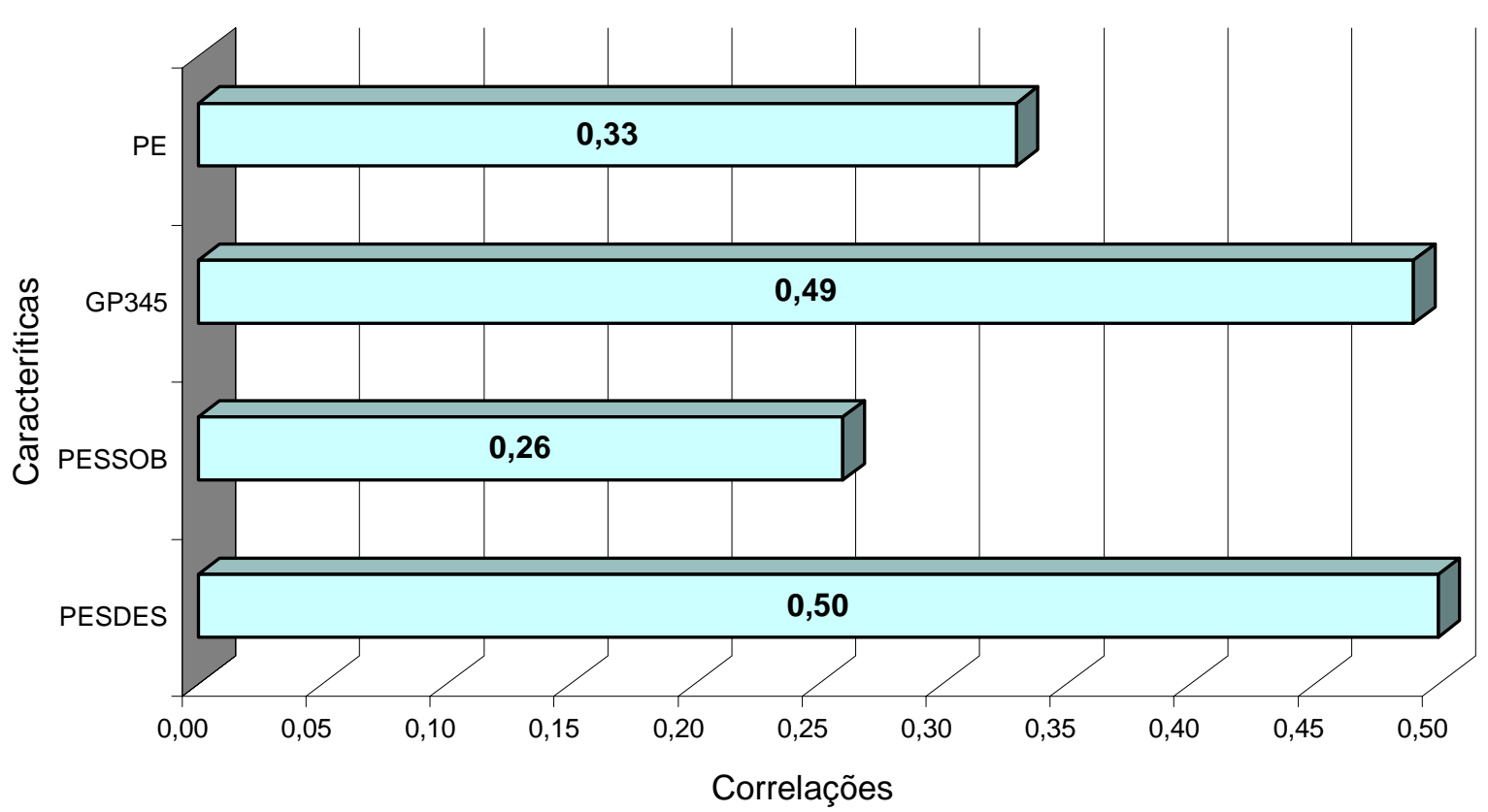

FIGURA 26 - Correlações genéticas entre AOL e características de desenvolvimento ponderal para o rebanho 2

Para as características PE e GP345 foi encontrada uma correlação genética próxima a zero indicando que essas características não influenciam a AOL no rebanho 1, para o rebanho 2, no entanto, os valores de correlação para PE $(0,33)$ e para GP345 $(0,49)$ indicam que a seleção para PE e GP345 terão um aumento em suas medidas de AOL. Tomando-se como base o cenário descrito no material e métodos e simulando-se ganhos genéticos correlacionados no rebanho2, após uma geração de seleção para AOL ter-se-ia um ganho de 0,3 cm na PE e para GP345 terse-ia um ganho de $5,1 \mathrm{~kg}$.

A correlação genética de AOL com peso ao sobreano em animais da raça Brangus foi de 0,41 (Moser et al., 1998) e os valores encontrados para os rebanhos 1 e 2 respectivamente foram de 0,27 e 0,26. Simulando-se os efeitos de seleção dos animais desses rebanhos para AOL, após uma geração ter-se-ia um ganho de 1,5 kg no PESSOB no rebanho 1 e de 2,0 kg no PESSOB para o rebanho2.

A correlação encontrada entre AOL e PESDES foi de 0,28 e 0,50 respectivamente para o rebanho 1 e 2 . Isto demonstra que selecionado-se para AOL obtém-se uma resposta positiva para PESDES. Estas correlações, apesar de 
magnitudes medianas, indicam que animais com maior peso a desmama tenderam a ter maiores áreas de olho de lombo. Quando se simulou a seleção para AOL obtevese um ganho correlacionado, para os rebanhos 1 e 2 respectivamente, de 0,9 $\mathrm{kg}$ e 4,0 kg/geração, no peso a desmama. Shepard et al. (1996) encontraram um valor superior $(0,42)$ aos valores encontrados neste trabalho.

A Correlação genética encontrada entre AOL e altura foi negativa indicando que animais de maior estatura terão menores AOL, possivelmente devido ao fato de que animais mais altos, na fase em que foram medidos, ainda se encontravam em fase de crescimento.

\subsubsection{CORRELAÇões GENÉticas de AOL COM EsCORES VisuAis}

As correlações de AOL com MUSC (0,22), CONF $(0,11)$ e PREC $(0.13)$ (Figura 27) foram positivas, portanto estes escores podem ser usados como critério de seleção para melhorar AOL, uma vez que a correlação genética positiva indica que quanto maior os escores visuais o touro melhor será a AOL de seus filhos. O valor encontrado para MUSC é igual ao encontro por Robinson et al. (1993).

Pela definição dada por Eler et al. (1996) o escore que melhor selecionaria AOL seria a musculosidade, como verificou-se neste trabalho e este escore tem a correlação de maior magnitude.

Para conformação verificou-se que a correlação encontrada é positiva, portanto condizente com a definição dada por Eler et al. (1996).

Para precocidade verificou-se que ela apresenta uma correlação positiva com AOL demonstrando que este escore visual pode estar avaliando musculatura em vez de deposição de gordura como é relatado por Eler et al. (1996). 


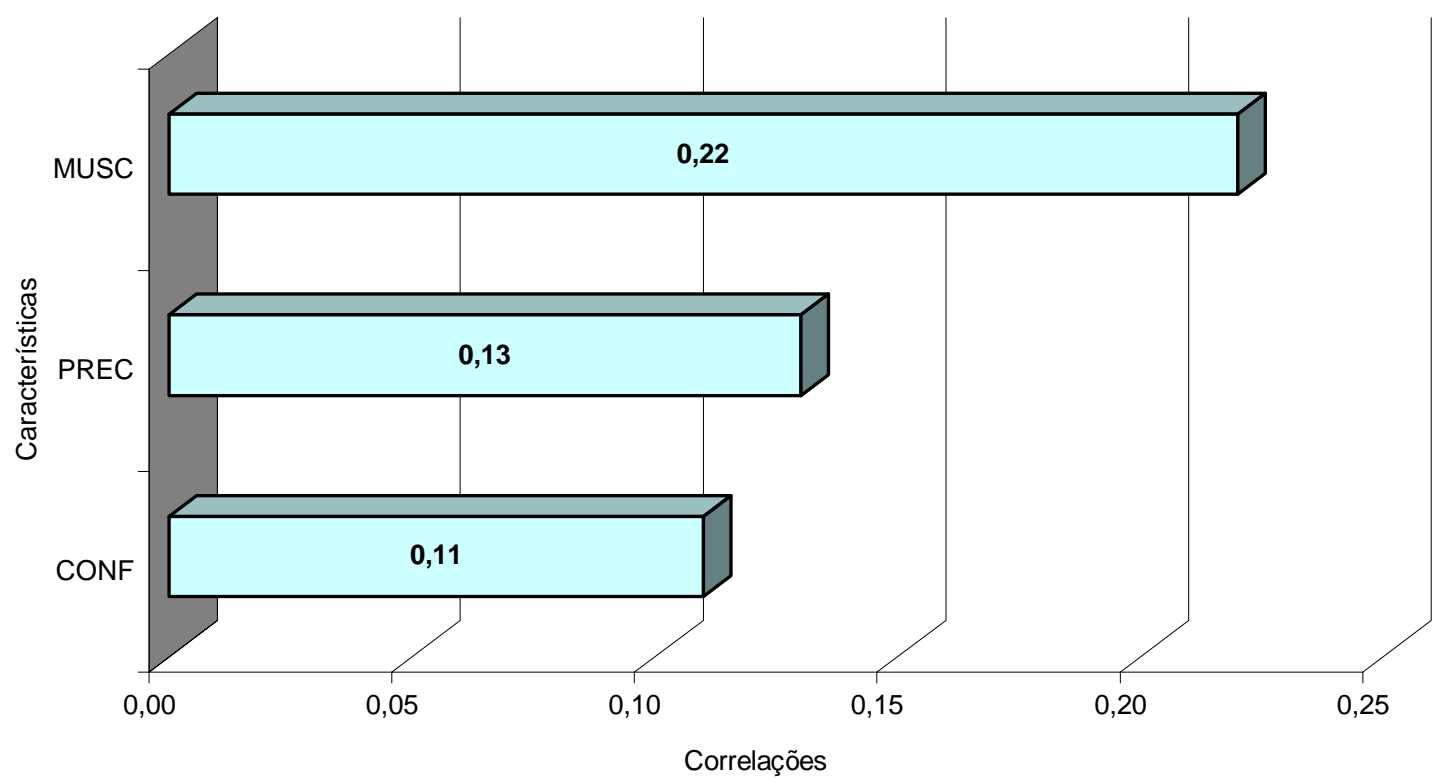

FIGURA 27 - Correlações genéticas entre AOL e escores visuais para o rebanho 1. 


\subsubsection{CORRELAÇÕES GENÉTICAS DE EGS COM CARACTERÍSTICA DE DESENVOLVIMENTO PONDERAL}

As correlações genéticas entre EGS e características de desenvolvimento ponderal são apresentadas nas Figura 28 (rebanho1) e 29 (rebanho2).

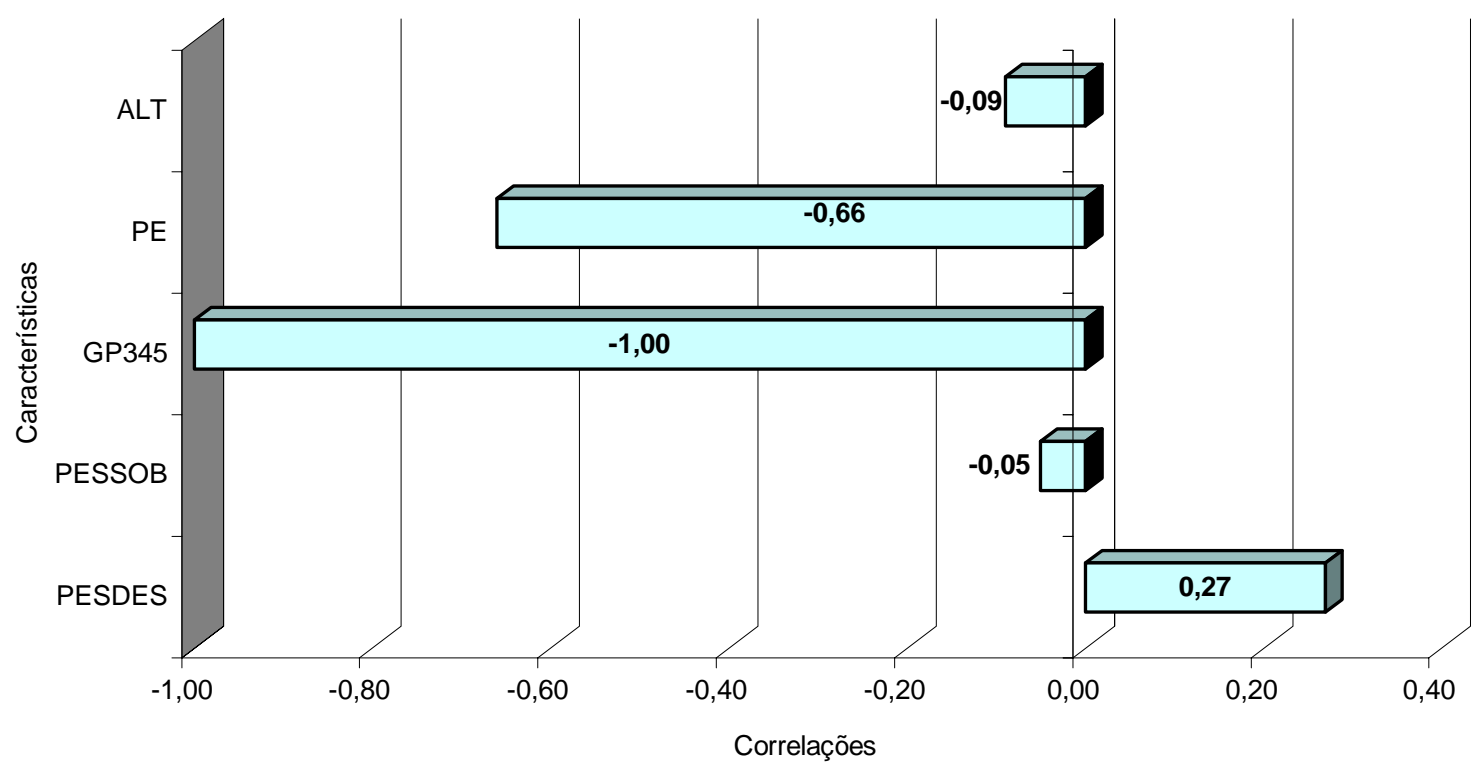

FIGURA 28 - Correlações genéticas entre EGS e características de desenvolvimento ponderal para o rebanho 1

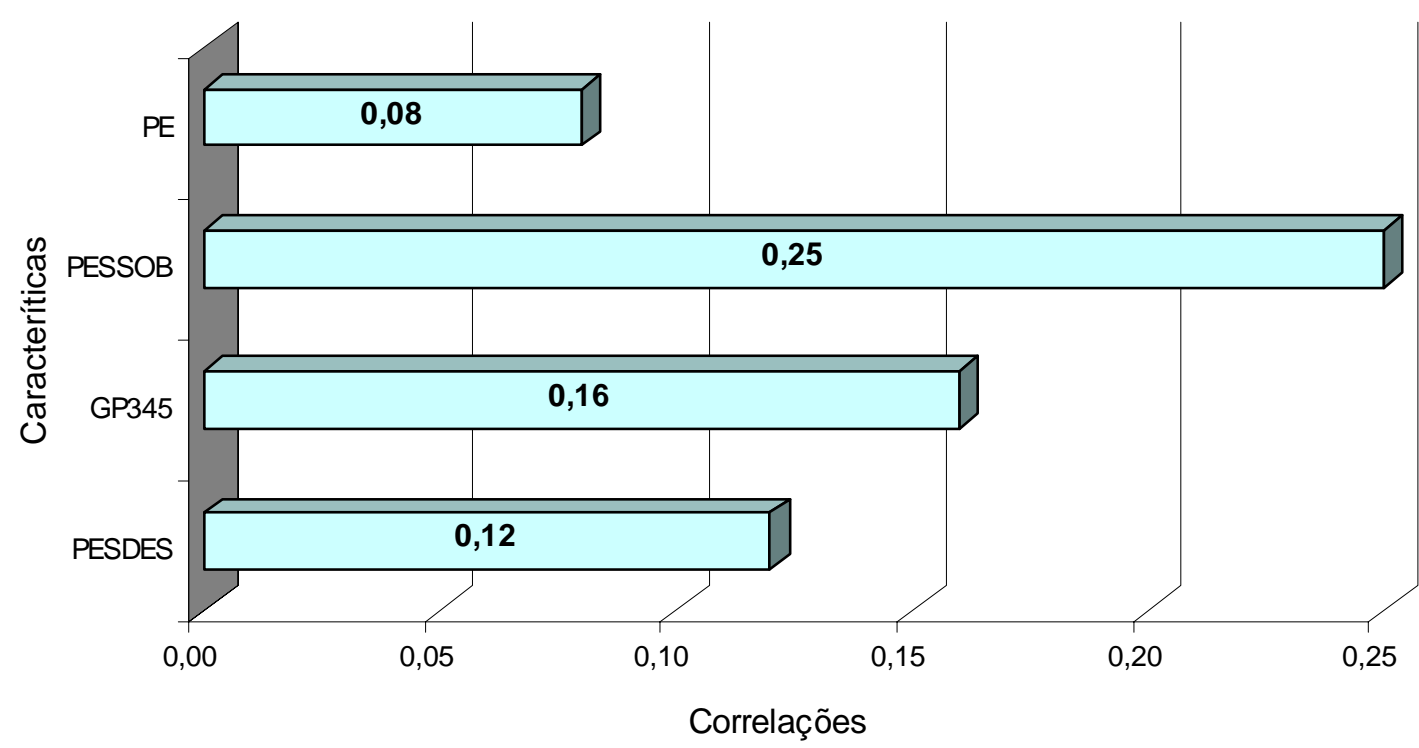

FIGURA 29 - Correlações genéticas entre EGS e características de desenvolvimento ponderal para o rebanho 2 . 
Estudando animais da raça Angus, Shepard et al. (1996) encontraram uma estimativa e 0,19 para a correlação genética entre peso a desmama e EGS valor este que é de direção igual e magnitudes diferentes dos que foram estimados para os rebanhos $1(0,27)$ e $2(0,12)$. Estas correlações sugerem que quando for feita a seleção para melhor acabamento não será comprometido a seleção para peso a desmama. Portanto para cada geração de seleção para EGS ter-se-á um ganho de 0,4 kg para o rebanho 1 e de $0,7 \mathrm{~kg}$ para o rebanho 2 .

Para GP345 a correlação genética sugere que animais com elevado ganho de peso terão deposição de gordura subcutânea tardia, no caso do rebanho 1 e para o rebanho 2 tem-se uma correlação positiva mas de baixa magnitude que sugere que animais com elevado ganho de peso poderão ter pequena alteração na EGS. No caso de rebanho 1 , possivelmente o modelo adotado não tenha se adaptado totalmente para estimação da correlação genética entre EGS e GP345, pois visto o valor estimado para tal correlação foi extremante elevado $(-1,00)$. Também o fato de uma grande parcela dos animais desse rebanho ser composta de filhos de reprodutores múltiplos tenha contribuído para esse resultado. Selecionado-se para EGS ter-se-ia, após uma geração, a perda de 1,8 kg no GP345 do rebanho 1 para o rebanho 2 teriase um ganho de $0,8 \mathrm{~kg}$.

A característica PESSOB foi correlacionada positivamente para o rebanho 2 com uma valor de 0,25 superior ao encontrado por Moser et al. (1998) com um valore de 0,11. Verificou-se que no rebanho 1 a EGS não influencia o PESSOB Quando seleciona-se para EGS, após uma geração ter-se-á uma perda de $-0,14$ kg para o rebanho 1 e de $1,80 \mathrm{~kg}$ para o rebanho 2 .

Para perímetro escrotal obteve uma correlação -0,66 com EGS no rebanho1 e de 0,08 no rebanho 2. Portanto estes valores sugerem que animais que forem selecionados para EGS terão uma diminuição na medida de PE no rebanho 1 e para o rebanho 2 a medida de PE não deve se alterar devido à baixa magnitude da correlação encontrada. Como resposta a seleção para estes casos ter-se-ia uma perda de 0,3 cm (rebanho 1) e um ganho, por geração, de 0,05 cm (rebanho 2).

O valor de correlação estimado para ALT sugere que esta característica não é pouco influenciada pela EGS. 


\subsubsection{CORRELAÇõES GENÉTICAS DE EGS COM ESCORES VISUAIS}

As correlações genéticas de EGS com escores visuais foram estimadas somente para o rebanho 1 e são apresentadas na Figura 30.

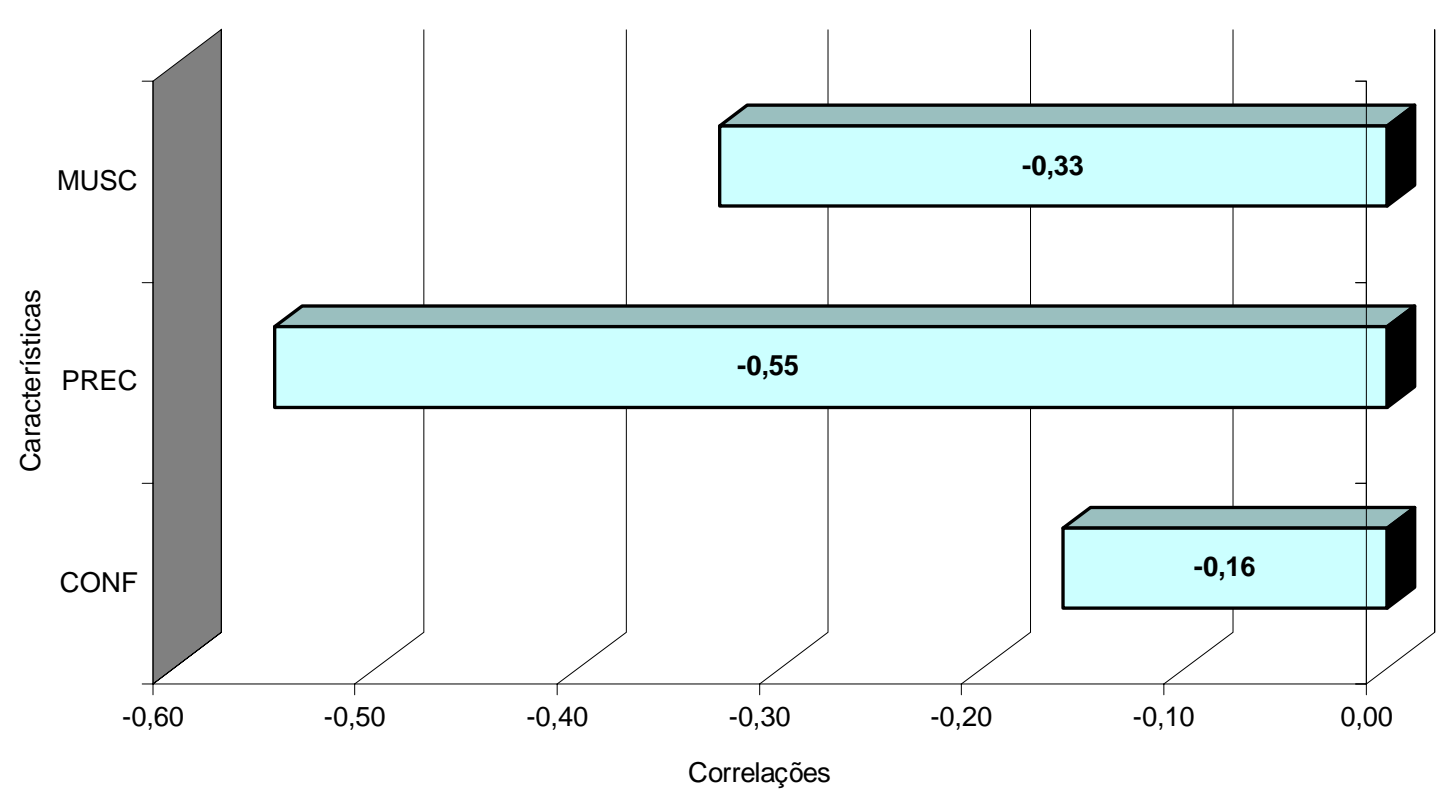

FIGURA 30- Correlações genéticas entre EGS e escores visuais para o rebanho 1.

As correlações encontradas entre EGS e os escores visuais de MUSC e CONF sugerem que estes estão consistentes com a definição dada por Eler et al. (1996) animais de maior musculatura tenderam a ter menos acabamento de gordura.

A correlação genética encontrada com PREC contradiz a definição da por Eler et al. (1996), portanto conclui-se que as medidas de escores de precocidade não foram precisas em avaliar a deposição de gordura subcutânea. 


\subsubsection{CORRELAÇÃo GENÉTICA ENTRE EGS E AOL}

As correlações genéticas entre EGS e AOL para o rebanho $1(-0,65)$ e $2(0,35)$ são apresentadas na Figura 31.

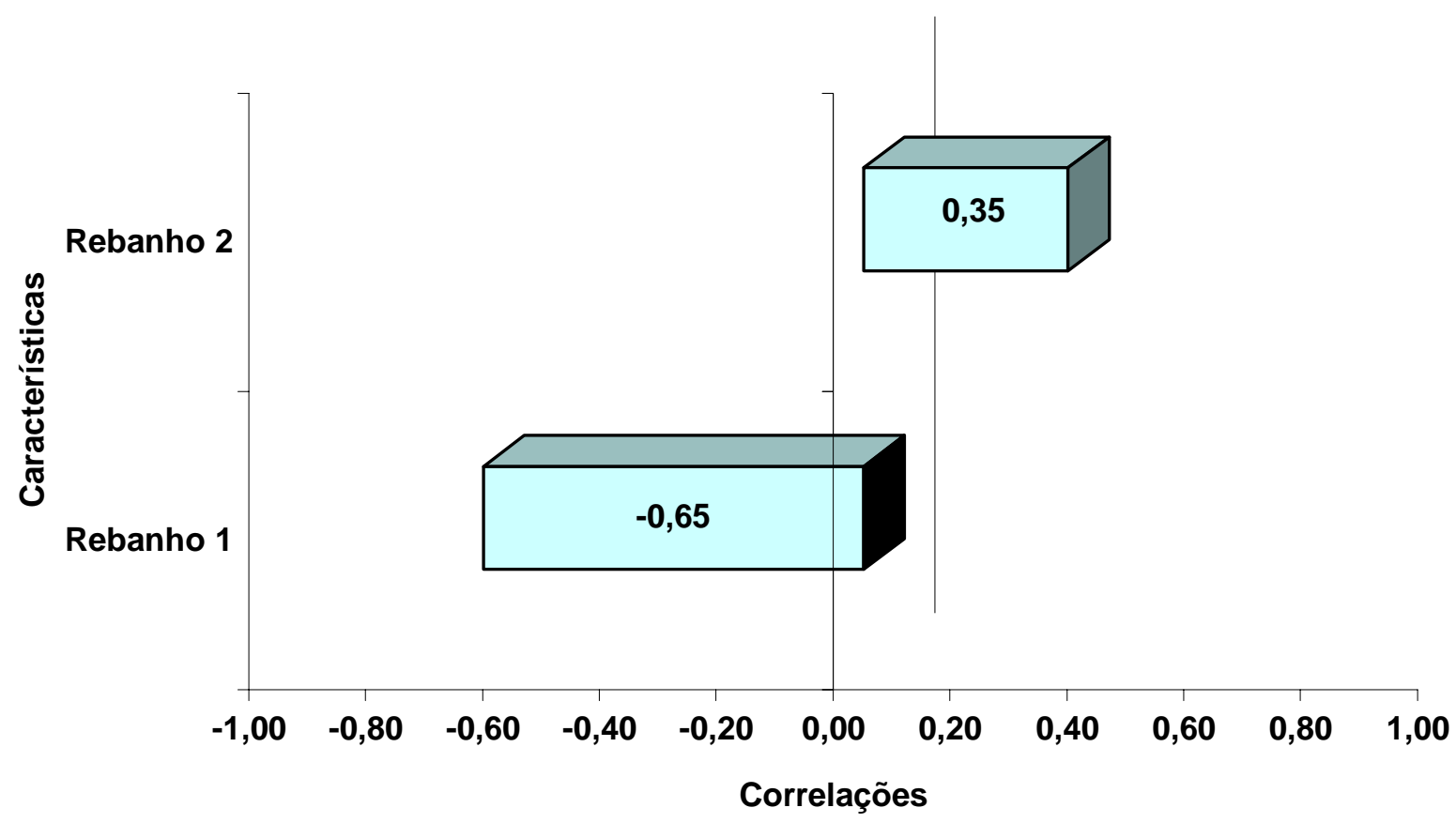

FIGURA 31 - Correlações genéticas entre EGS e AOL para o rebanho 1 e 2.

Verifica-se que existe uma grande variabilidade nas correlações encontradas para as características. Além disto verificou-se que há variação quando analisamos rebanhos diferentes.

Os resultados da literatura também são dispares. O valor encontrado para o rebanho 1 é similar ao encontrado por Reverter et al. (2000) para a raça Hereford e para o rebanho 2 o valor é similar ao relatado por Robinson et al. (1993).

Com os valores de correlações encontrados, simulando-se a seleção das características AOL e EGS, ter-se-ia os seguintes resultados:

Quando se seleciona AOL a resposta correlacionada de seleção após uma geração seria -0,05 mm/ger para o rebanho 1 e de 0,03 mm/ger para o rebanho 2 .

Para o caso em que a seleção seja baseada na característica EGS a resposta correlacionada de seleção após uma geração seria -0,4 cm2/ger para o rebanho 1 e de $0,5 \mathrm{~cm} 2 /$ ger para o rebanho 2 . 


\section{CONCLUSÕES}

1) As estimativas de herdabilidade para as características área de olho de lombo e espessura de gordura subcutânea, sugerem que pode-se obter progresso genético com a seleção.

2) Deve-se realizar medidas em fêmeas e não somente em machos inteiros, pois as fêmeas depositam gordura a uma idade mais jovem. Estas medidas levariam a uma maior precisão na seleção de touros.

3) Deve-se estudar novas metodologias de analise para os dados de EGS.

4) Há necessidade de aperfeiçoar a utilização dos escores visuais em conjunto com a ultra-sonografia.

5) Há necessidade de estabelecer equações que permitam estimar o rendimento de carcaça a partir das medidas de ultra-sonografia. Isto permitiria selecionarmos touros que transmitam o melhor rendimento a uma idade préestabelecida.

6) A grande variabilidade genética encontrada para as características tanto na literatura como no presente trabalho sugerem que mais pesquisas e maior atenção devem ser dadas a estas características. 


\section{REFERÊNCIAS BIBLIOGRÁFICAS}

ANUALPEC. Anuário da pecuária brasileira, FNP Consultoria e Comércio, editora Argos, 2000. 392p.

BAILEY, C.M.; JESEN, J.; ANDERSEN, B.B. Ultrasonic scanning and body measurements for predicting composition and muscle distribution in young Holstein $\mathrm{x}$ Friesian bulls. J. Anim. Sci., v.63, p. 1337 - 1346, 1986.

BANG, K.S.; YOON, J.K.; KIM, Y.K. Ultrasonic backfat measuremenet in Korean Native cattle. Korean Journal of Animal Science ,Department of Animal Science, Dong-A University, v. 36, n.4, p. 409-414, 1994.

BARROS, M.A. Avaliação "in vivo" de carcaças bovinas. Pirassununga - SP, Faculdade de Zootecnia e Engenharia de Alimentos - USP, Seminário, 1993.

BIFFANI, S.; MARTINS FILHO, R; GIORGETTI, A. et al. Fatores ambientais e genéticos sobre o crescimento ao ano e ano sobreano de bovinos Nelore, criados no Nordeste do Brasil. Rev. Brás. Zootec., v.28, p479-484, 1999.

BOGGS, D.L.; MERKEL, A.R. Live animal carcass evaluation en selection manual. 3.ed. Dubuque, Iowa, Kendall/Hunt Publishing Co., 1990. 211p. 
BOLDMAN, K.G.; KRIESE, L.A.; VAN VLECK, L.D.; KACHMAN, S.D. A manual for use of MTDFREML: a set of programs to obtain estimates of variances and covariances. USDA-ARS, 1993.

BRETHOUR, J.R. The repeatibility and accuracy of ultrasound in measuring backfat of cattle. J. Anim. Sci., v.70, p. 1039 - 1044, 1992.

CROSS, H.R. Advances in ultrasound prosedures for determinid carcass merit in catle. In: PROC. BEEF IMPROV. Feed-Res. Symp.and Amnu. Mtg., Nashiville, Tn, 1989.

ELER, J.P.; VAN VLECK, L.D.; FERRAZ, J.B.S.; LÔBO, R.B. Estimation of Variances due to direct an maternal effects for growth traits of Nelore cattle. J. Anim. Sci., v.73, p. 3253 - 3258, 1995.

ELER, J.P.; FERRAZ, J.B.S.; SILVA, P.R. Parâmetros genéticos para peso, avaliação visual e circunferência escrotal na raça Nelore, estimado por modelo animal. Arq. Bras. Med. Vet. Zootec.,v.48, n.2, p.203-213, 1996.

FARO, L. Melhoramento genético de suínos. Jaboticabal - SP, FCAVJ - UNESP, Seminário, 1993.

FERRAZ J.B., E ELER J.P. Sumário de touros Nelore 2000 Pirassununga : FZEA/GMA, 2000. 60p.

GEORGE, A.; LIU, J.; NG, E. User guide for SPARSPACK: Waterloo sparse linear equations package. CS-78-30, Dept. Computer Sci., Univ. Waterloo, ON, Canada, 1980. 
GRESSLER, S.L.; BERGMANN, J.A.G.; PENA, V.M. et al Estudo das associações genéticas entre perímetro escrotal e características reprodutivas de fêmeas da raça Nelore. In REUNIÃO ANUAL DA SOCIEDADE BRASILEIRA DE ZOOTECNIA, 35., Botucatu, 1998 Anais Botucatu: SBZ, v.3, 1998. p.368-370.

HASSEN, A.; WILSON, D.E. Genetic evaluation for growth and maternal traits. [on line] Disponível na Internet via http://www.angus.org/sireeval/genintro.html. Capturado em 18 de abril de 2001.

JOHNSON, M.Z.; SCHALLES, R.R.; DIKEMAN, M.E. GOLDEN, B.L. Genetic parameter estimates of ultrasound-measured longissimus mucle area and $12^{\text {th }}$ rib fata thichness in brangus cattle. J. Anim. Sci., v.71, p. 2623 - 2630, 1993.

JOSAHKIAN, Luiz Antonio. Programa de Melhoramento Genético das Raças Zebuínas. In SIMPÓSIO PECUÁRIA 2000 - PERSPECTIVAS PARA O III MILÊNIO, 1., Pirassununga, 2000.Anais. Pirassununga : FZEA-USP, 2000. 1 CD-ROM

KOURY FILHO, W.; FERRAZ, J.B.S; ELER, J.P.; BORGATTI, L.M.O Importância do uso de escores avaliação visuais e medidas mofométricas em programas de seleção em bovinos de corte. In CONGRESSO BRASSILEIRO DAS RAÇAS ZEBUÍNAS, 4., Uberaba, 2000 Anais. Uberaba, 2000, p.342-346

KOURY FILHO, W. Análise genética de escores de avaliação visuais e suas respectivas relações com desempenho ponderal na raça Nelore. Pirassununga, 2001. 82p. Tese (Mestrado) - Faculdade de Zootecnia e Engenharia de Alimentos, Universidade de São Paulo.

LÔBO, R.N.B.; MADALENA, F.E.; VIEIRA, A.R. Average estimates of genetic parameters for beef and dairy cattle in tropical regions. Anim. Breeding Abstr., v.68, n.6 p.433-462, 2000. 
LUCHIARI FILHO, A. Pecuária da carne bovina 1ed. São Paulo, 2000. 134p.

LUZ_E_SILVA, S., Relatório de estágio curricular na área de avaliação animal pela técnica de ultra-sonografia real-time. Rio Grande do Sul:PUCRS, 1995. 67p. anexos./relatório

MOSER , D.W.; BERTRAND, J.K.; MIZTAL, I.; KRIESE, L.A.; BENYSHEK, L.L.; Genetic parameter estimates for carcass and yearling ultrasound measurements in Brangus cattle. J. Anim. Sci. V.76, p.2542-2548, 1998.

NELDER, J.A.; MEAD, R. A simplex method for function minimization. Computer J., v.5, p.147-151, 1965.

PEREIRA, E. Análise genética de algumas características reprodutivas e de suas relações com desempenho ponderal na raça Nelore. Pirassununga, 2000. 64p. Tese (Mestrado) - Faculdade de Zootecnia e Engenharia de Alimentos, Universidade de São Paulo.

PREKINS, T.L.; GREEN, R.D.; HAMLIM, K.E.; SHEPARD, H.H.; MILLER, M.F. Ultrasonic prediction of carcass merit in beef cattle: Eavluation of thenician effects on ultrasonic estimates of carcass fat thickness and longissimus muscle area. $\mathbf{J}$. Anim. Sci. V.70, p.2758-2765, 1992.

PRESS, W.H.; FLANNERY, B.P.; TEUKOLSKY, S.A.; VETTERLING, W.T. Numerical recipes. Cambridge University Press, Cambridge, MA.

QUIRINO, C.R.; BERGMANN, J.A.G. Heritability of scrotal circumference adjusted and unadjusted for body weight in Nellore bulls, using univariate and bivariate animal models. Theriogenology, v.49, p.1389-1396, 1998. 
RENAND, G.; FISHER, A.V. Comparison of methods for estimating carcass fat content of young Charolais bulls in preformance testing station. Livestock Productuion Science v.51 p.205-213, 1997.

REVERTER, A.; JOHNSTON, D.J.; GRASER, H.U.; WOLCOTT, M.L.; UPTON, W.H. Genetic analyses of live-animal ultrasound and abattoir carcass traits in Australian Angus and Hereford cattle. J. Anim. Sci. V.78, p.1786-1795, 2000.

ROBINSON, D.L.; McDONALD, C.A.; HAMMOND, K.; TURNER, J. W. Live animal measuremenet of carcass traits by ultrasound: Assessment and accuracy of sonographers. J. Anim. Sci.V. 70, p.1667-1676, 1992.

SAVIANNI, C.M. Análise da carcaça suína “in vivo”. Pirassununga - SP, Faculdade de Zootecnia e Engenharia de Alimentos - USP, Seminário, 1993.

SHEPARD, H.H.; GREEN, R.D.; GOLDEN, B.L.; HAMLIM, K.E.; PREKINS, T.L.; DILES, J.B. Genetic parameter estimates of live animal ultrasonic measures of retail yield indicators in yearling breending cattle. J. Anim. Sci. V. 74, p.761-768, 1996.

SMITH, M.T.; OLTJEN, J.W.; GILL, D.R.; DOLEZAL, H.G.; KROPP, J.R.;McPEAKE, C.A.; BEHRENS, B.D. Ultrasound and visual appraisal as methods to account for variantion in performance and carcass parameters in feedlot steers. Anim. Sci. Res. Rep., Agric .Exp. Station, Oklahoma State University, n.MP-127, p.3127-136, 1989b.

SMITH, S.P.; GRASER, H.U. Estimating variance components in a class of mixed models by restricted maximum likelihood. J. Dairy Sci., v.69, p.1156-1165, 1986. 
STRASIA, C.A.; DOLEZAL, H.G.; SMITH, M.T.; FOUTZ, C.P.; GILL, D.R.; BEHRENS, B.D.; LLOYD, R.M.; SKAGGS, B.J.; SCHEMM, R.L.; SCHULTZ,C.L.; DEEN,D.L. Correlations of ultrasound and measured fat thickness in feedlot heifers. Anim. Sci. Res. Rep., Agric. Exp. Station, Oklahoma State University, n. MP-127, p. 151-153, 1989.

TURNER, J.W.; PELTON, L.S.; CROSS, H.R. Using live animal ultrasound measures of ribeye area and fat thickness in yearling Hereford bulls. J. Anim. Sci. V. 68, p.3502-3506, 1990.

WALDNER, D.N.; DIKEMAN, M.E.; SCHALLES, R.R.; OLSON, W.G.; HOUGHTON, P.L.; UNRUH, J.A.; CORAH, L.R. Validation of real-time ultrasound technology for predicting fat thickness, longissimus muscle areas, and composition of Brangus bulls from 4 months to 2 years age. J. Anim. Sci. V. 70, p.3044, 1992.

WILSON, D.E. Application os Ultrasound for Genetic Improvement. J. Amin. Sci., v. 70, n.3, p. 973 - 983, 1992. 